\title{
First Observation of Defined Structural Motifs in the Sulfur-Iodine Thermochemical Cycle and Their Role in Hydrogen Production
}

\author{
Víctor H. Ramos-Sánchez, ${ }^{1,2}$ John Tomkinson, ${ }^{3}$ Jesús Muñiz-Soria, ${ }^{2}$ \\ Edgar Valenzuela, ${ }^{2}$ and Robin Devonshire ${ }^{1}$ \\ ${ }^{1}$ High Temperature Science Laboratories, Department of Chemistry, The University of Sheffield, Sheffield S3 7HF, UK \\ ${ }^{2}$ Programa Académico de Ingeniería en Energía, Universidad Politécnica de Chiapas, Calle Eduardo J. Selvas S/N, Col. Magisterial, \\ 29010 Tuxtla Gutiérrez, Chis, Mexico \\ ${ }^{3}$ ISIS Pulsed Neutron and Muon Source, Science and Technology Facilities Council, Rutherford Appleton Laboratory, \\ Didcot OX11 0QX, UK
}

Correspondence should be addressed to Víctor H. Ramos-Sánchez, vhramos@upchiapas.edu.mx

Received 14 February 2011; Accepted 27 March 2011

Academic Editor: Ahmed Aamouche

Copyright (c) 2011 Víctor H. Ramos-Sánchez et al. This is an open access article distributed under the Creative Commons Attribution License, which permits unrestricted use, distribution, and reproduction in any medium, provided the original work is properly cited.

The present paper investigates the ionic species coexisting in the $\mathrm{HI}_{x}$ feed of the sulfur-iodine thermochemical cycle. For this purpose, Raman and inelastic neutron scattering as well as molecular modelling were applied to the study of the binary $\mathrm{HI}-\mathrm{H}_{2} \mathrm{O}$ system and the ternary $\mathrm{HI}-\mathrm{I}_{2}-\mathrm{H}_{2} \mathrm{O}$ and $\mathrm{KI}-\mathrm{I}_{2}-\mathrm{H}_{2} \mathrm{O}$ systems. Raman spectra, obtained at $298 \mathrm{~K}$, strongly suggest the coexistence of $\mathrm{I}_{3}^{-}, \mathrm{I}^{-}\left(\mathrm{I}_{2}\right)$, and $\mathrm{I}^{-}\left(\mathrm{I}_{2}\right)_{2}$ species. Whereas on the other hand, inelastic neutron scattering spectra $(20 \mathrm{~K})$ revealed, for the first time, evidence for the presence of discrete water structural motifs under specific conditions. Molecular modelling of two idealized structures has allowed us to establish a reasonable interpretation of the important structural motifs in these systems, in terms of the azeotrope of the $\mathrm{HI}-\mathrm{H}_{2} \mathrm{O}$ system and the pseudoazeotrope of the $\mathrm{HI}-\mathrm{I}_{2}-\mathrm{H}_{2} \mathrm{O}$ system.

\section{Introduction}

Thermochemical cycles (TC), which decompose feedwater to generate hydrogen and oxygen, are a promising route to the large-scale hydrogen production. The primary product of these closed-cycle chemical reactions, hydrogen, is both a carbon-free energy source and a valuable reagent gas (N.B. the current industry annual demand for hydrogen is of about 0.1 Gton, of which only $2 \%$ is produced from renewable sources) [1-3].

The TC that has attracted the most attention worldwide is the sulfur-iodine cycle (SI-TC), the first stage of which is the exothermic Bunsen reaction:

$$
2 \mathrm{H}_{2} \mathrm{O}+\mathrm{SO}_{2}+\mathrm{I}_{2} \longrightarrow \mathrm{H}_{2} \mathrm{SO}_{4}+2 \mathrm{HI}
$$

This is followed by two endothermic reactions, one for each of the two reaction products, $\mathrm{H}_{2} \mathrm{SO}_{4}$ and $\mathrm{HI}$. The decomposition reaction for $\mathrm{H}_{2} \mathrm{SO}_{4}$

$$
2 \mathrm{H}_{2} \mathrm{SO}_{4} \longrightarrow 2 \mathrm{H}_{2} \mathrm{O}+2 \mathrm{SO}_{2}+\mathrm{O}_{2}
$$

requires high temperatures whilst the decomposition reaction for $\mathrm{HI}$

$$
2 \mathrm{HI} \longrightarrow \mathrm{H}_{2}+\mathrm{I}_{2}
$$

requires only modest temperatures. Overall, this three-step scheme is seen to regenerate the reagents, $\mathrm{SO}_{2}$ and $\mathrm{I}_{2}$, whilst splitting water into $\mathrm{H}_{2}$ and $\mathrm{O}_{2}$ gases.

It was discovered by General Atomics in the late 1970s that when the Bunsen reaction was operated with excess $\mathrm{H}_{2} \mathrm{O}$ and $\mathrm{I}_{2}$, a spontaneous separation into two aqueous acid 
phases occurred. The lighter phase contained predominantly $\mathrm{H}_{2} \mathrm{SO}_{4}$, and the heavier phase containing most of the $\mathrm{HI}[4$, 5]. This gravity-driven phase separation makes an important contribution to the overall efficiency of the SI-TC. Under these reaction conditions it is more realistic to represent the Bunsen separation, Reaction (1), as follows:

$$
\begin{aligned}
16 \mathrm{H}_{2} \mathrm{O} & +\mathrm{SO}_{2}+9 \mathrm{I}_{2} \\
& \longrightarrow\left(\mathrm{H}_{2} \mathrm{SO}_{4}+4 \mathrm{H}_{2} \mathrm{O}\right)^{(\mathrm{i})}+\left(2 \mathrm{HI}+10 \mathrm{H}_{2} \mathrm{O}+8 \mathrm{I}_{2}\right)^{(\mathrm{ii})}
\end{aligned}
$$

where (i) represents the lighter $\mathrm{H}_{2} \mathrm{SO}_{4}$-rich phase, and (ii) represents the heavier HI-rich phase, referred to here as the $\mathrm{HI}_{x}$ phase, or simply $\mathrm{HI}_{x}[4,6]$. The two phases (i) and (ii) are the respective feeds to the separate $\mathrm{H}_{2} \mathrm{SO}_{4}$ and $\mathrm{HI}$ decomposition stages of the SI-TC. The conditions of temperature and composition necessary for the $\mathrm{H}_{2} \mathrm{O}-\mathrm{I}_{2}-\mathrm{HI}-$ $\mathrm{H}_{2} \mathrm{SO}_{4}$ system to produce the phase separation, and the compositions of the separate phases, have been investigated $[7,8]$.

1.1. General Description of the System. The phase diagram of the $\mathrm{HI}-\mathrm{I}_{2}-\mathrm{H}_{2} \mathrm{O}$ ternary system at room temperature is given in Figure 1 and shows four distinct phases. Under typical reaction conditions, and except for traces of the sulfur-containing species, the $\mathrm{HI}_{x}$ phase of the SI-TC has the following mole fraction composition [9]: $x_{\mathrm{HI}}=0.10$; $x_{\mathrm{I}_{2}}=0.40 ; x_{\mathrm{H}_{2} \mathrm{O}}=0.50$, and is seen in Figure 1 to lie in the liquid-solid region of the room temperature system. Phase diagrams for the $\mathrm{HI}-\mathrm{I}_{2}-\mathrm{H}_{2} \mathrm{O}$ system at higher temperatures have been estimated [5]. These support observations that at temperatures typical for the Bunsen reaction, $120^{\circ} \mathrm{C}$, the $\mathrm{HI}_{x}$ composition lies in the homogenous liquid phase, a phase which becomes lower in $x_{\mathrm{H}_{2} \mathrm{O}}$, and higher in $x_{\mathrm{I}_{2}}$, with increasing temperature [5].

To produce $\mathrm{H}_{2}$ gas from the $\mathrm{HI}_{x}$ feed of the Bunsen reaction via Reaction (3) it is necessary to reduce both the $\mathrm{I}_{2}$ and $\mathrm{H}_{2} \mathrm{O}$ mole fractions. Although the spontaneous phase separation in the GA SI-TC is potentially highly advantageous for the overall cycle efficiency, a problem arises from the high, ca. 5.0, $x_{\mathrm{H}_{2} \mathrm{O}} / x_{\mathrm{HI}}$ mole ratio in $\mathrm{HI}_{x}$. This is close to the $x_{\mathrm{H}_{2} \mathrm{O}} / x_{\mathrm{HI}}$ mole ratio in the HI- $\mathrm{H}_{2} \mathrm{O}$ azeotrope, 5.8 at $25^{\circ} \mathrm{C}[10]$. As a consequence, it is not possible to concentrate the HI by straightforward distillation, and other means are being explored, for example, using phosphoric acid [4] and membrane separation [11].

1.2. Species Present in the $\mathrm{HI}-\mathrm{I}_{2}-\mathrm{H}_{2} \mathrm{O}$ System. The species present in the $\mathrm{HI}-\mathrm{H}_{2} \mathrm{O}[8,12]$ and $\mathrm{HI}-\mathrm{I}_{2}-\mathrm{H}_{2} \mathrm{O}[13]$ systems have been investigated previously using Infrared and Raman spectroscopy but molar compositions close to that of the $\mathrm{HI}_{x}$ phase of the SI-TC were not considered.

A recent spontaneous raman scattering (SRS) study has specifically addressed the issue of which $\mathrm{I}_{2}$-containing species are present in the $\mathrm{HI}_{x}$ region of the $\mathrm{HI}-\mathrm{I}_{2}-\mathrm{H}_{2} \mathrm{O}$ phase diagram. The homogeneous liquid phase compositions that exist within the scope of the partial phase diagram, shown

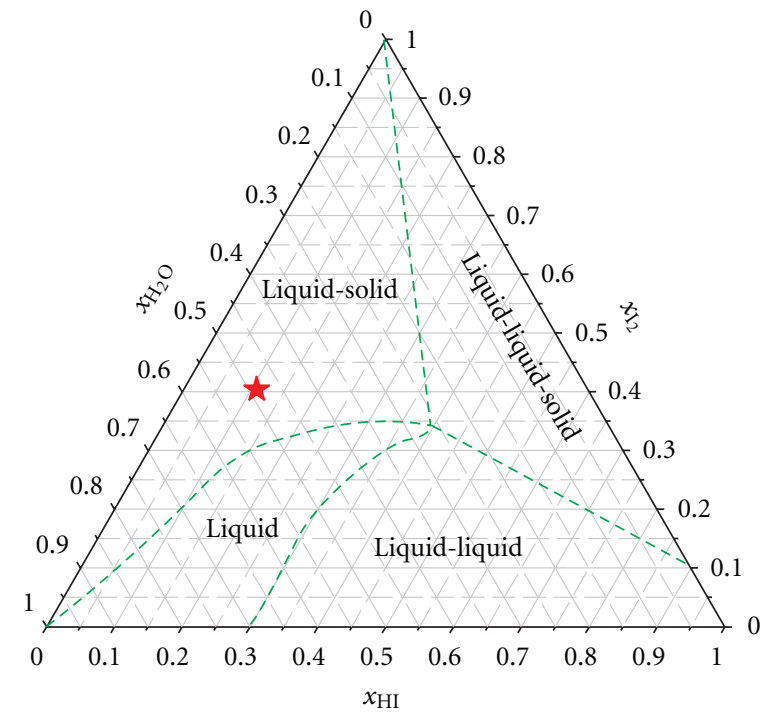

FIGURE 1: Ternary phase diagram of the $\mathrm{HI}-\mathrm{I}_{2}-\mathrm{H}_{2} \mathrm{O}$ system showing the four phases occurring at $297 \mathrm{~K}$ [5]. The composition of the $\mathrm{HI}_{x}$ phase in the GA SI-TC is allocated with a star.

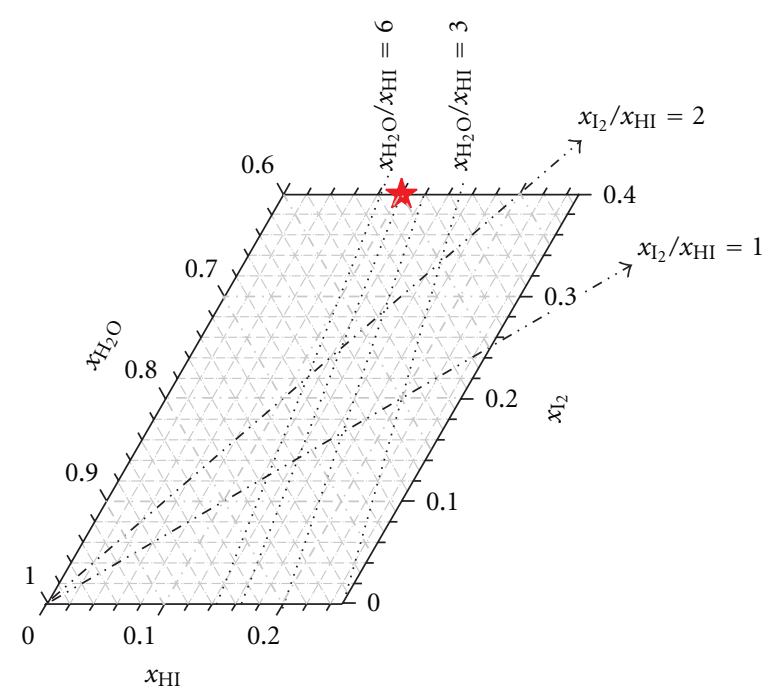

FIGURE 2: A truncated ternary phase diagram of the $\mathrm{HI}-\mathrm{I}_{2}-\mathrm{H}_{2} \mathrm{O}$ system superimposed with lines of different constant $x_{\mathrm{I}_{2}} / x_{\mathrm{HI}}$ and $x_{\mathrm{H}_{2} \mathrm{O}} / x_{\mathrm{HI}}$ mole ratios. This diagram delimitates the region of interest of the present study.

in Figure 2, were investigated over a range of different temperatures [14].

The Raman activity of the $\mathrm{I}_{2}$-containing species present in the system made it possible to rationalise the observations in terms of the following hydrated species: $\mathrm{I}^{-}$; symmetric $\mathrm{I}_{3}{ }^{-}$; unsymmetric $\mathrm{I}_{3}{ }^{-}\left(\mathrm{I}^{-}\left(\mathrm{I}_{2}\right)\right) ; \mathrm{I}_{5}^{-}\left(\mathrm{I}^{-}\left(\mathrm{I}_{2}\right)_{2}\right)$. The relative dominance of the various polyiodide species was found to depend on the mole ratio $x_{\mathrm{I}_{2}} / x_{\mathrm{HI}}$. When $x_{\mathrm{I}_{2}} / x_{\mathrm{HI}} \leq 1$, the $\mathrm{I}^{-}\left(\mathrm{I}_{2}\right)$ predominates; when $x_{\mathrm{I}_{2}} / x_{\mathrm{HI}}$ is between 1 and 2 the species $\mathrm{I}^{-}\left(\mathrm{I}_{2}\right)$ and $\mathrm{I}^{-}\left(\mathrm{I}_{2}\right)_{2}$ are both important; when $x_{\mathrm{I}_{2}} / x_{\mathrm{HI}} \geq$ 2 the $\mathrm{I}^{-}\left(\mathrm{I}_{2}\right)_{2}$ species predominates. Lines of constant $x_{\mathrm{I}_{2}} / x_{\mathrm{HI}}$ are straight lines emanating from the corner of the phase diagram where $x_{\mathrm{H}_{2} \mathrm{O}}$ is 1.0. In Figure 2, lines for the fixed $x_{\mathrm{I}_{2}} / x_{\mathrm{HI}}$ mole ratios, 1 and 2 , are drawn. 
A further influence on local structures present in the homogenous fluid phase of the $\mathrm{HI}-\mathrm{I}_{2}-\mathrm{H}_{2} \mathrm{O}$ system, the region of our interest to the SI-TC, is the mole ratio $x_{\mathrm{H}_{2} \mathrm{O}} / x_{\mathrm{HI}}$. Previous ab initio calculations have identified stable aquocomplexes of isolated, neutral $\mathrm{HI}$, and the ion pair $\mathrm{H}^{+} \mathrm{I}^{-}$. These complexes were found to be most stable for $x_{\mathrm{H}_{2} \mathrm{O}} / x_{\mathrm{HI}}$ mole ratios of 3 and 4, respectively [15]. Lines of constant $x_{\mathrm{H}_{2} \mathrm{O}} / x_{\mathrm{HI}}$ mole ratio for integer values $3,4,5$, and 6 are shown in Figure 2 (these lines encompass the $\mathrm{HI}-\mathrm{H}_{2} \mathrm{O}$ azeotrope, see above). It is clear that the relative amount of water available to interact with $\mathrm{I}_{2}$-containing species of any kind is important in interpreting the solvation structures present in the homogeneous fluid region and it is anticipated that a hexa-aquo complex will be important in diluted systems.

In the case of the present paper we shall use molecular models of the $\mathrm{HI}-\mathrm{H}_{2} \mathrm{O}$ and $\mathrm{HI}-\mathrm{I}_{2}-\mathrm{H}_{2} \mathrm{O}$ systems to explore their dynamics. Also, in order to assist in such molecular insights we shall consider the $\mathrm{KI}-\mathrm{I}_{2}-\mathrm{H}_{2} \mathrm{O}$ system, which by comparison to the $\mathrm{HI}-\mathrm{I}_{2}-\mathrm{H}_{2} \mathrm{O}$ system will ease the discrimination of the spectral contribution from the counterion $\mathrm{H}^{+}$; as well as the evaluation of concentration regimes with $x_{\mathrm{H}_{2} \mathrm{O}} / x_{\mathrm{I}^{-}}$mole ratios below 3.5 , which due to commercial availability of hydriodic acid are not achievable for the ternary system $\mathrm{HI}-\mathrm{I}_{2}-\mathrm{H}_{2} \mathrm{O}$.

1.3. Vibrational Spectroscopy. Bulk liquid water and aqueous solutions have been thoroughly investigated using vibrational spectroscopy. Infrared spectroscopy and SRS have both been used to determine hydrogen bond distances [16], with SRS being especially useful to study local structures, for example, water clusters or hydrated ions, within bulk liquid water due to its sensitivity to short-range interactions [17]. SRS has been widely exploited in structural investigations of water and aqueous solutions containing a wide variety of electrolytes [17].

Inelastic neutron scattering (INS), on the other hand, provides an alternative view of the vibrational spectra of ionic aqueous solutions. INS is free of resonance effects, has high sensitivity to hydrogen atom vibrations, and has a very wide spectral range from 16 to $4000 \mathrm{~cm}^{-1}$. Its freedom from optical selection rules enables it to observe vibrational modes that are inactive in optical spectra. Recent developments in INS instrumentation have improved access to the intermolecular motions of the water ice phases [18]. Measured INS spectral intensities are directly comparable with those calculated from the output of modern ab initio programs and this explains the common practice of using these programs to understand INS results [19].

The objective of the present paper is to exploit the benefits of INS to study the $\mathrm{HI}_{x}$ phase of the SI-TC in combination with optical techniques. Data from both the liquid and the glassy states of samples of the $\mathrm{HI}-\mathrm{H}_{2} \mathrm{O}, \mathrm{HI}-\mathrm{I}_{2}$ $\mathrm{H}_{2} \mathrm{O}$ and $\mathrm{KI}-\mathrm{I}_{2}-\mathrm{H}_{2} \mathrm{O}$ systems are presented, and qualitative interpretation is given in terms of the dynamics of the molecules involved. Our final objective will be to attain an initial insight into the chemical structures involved in the occurrence of the azeotropes in the $\mathrm{HI}-\mathrm{H}_{2} \mathrm{O}$ and the $\mathrm{HI}-\mathrm{I}_{2}-$ $\mathrm{H}_{2} \mathrm{O}$ systems.

\section{Experimental}

Measured amounts of potassium iodide, iodine, and $\mathrm{HI}_{57}$ (hydriodic acid $57 \mathrm{wt} \%$ ), or $\mathrm{HI}_{67}$ (hydriodic acid $67 \mathrm{wt} \%$ ) were added to volumetric flasks and made up with deionised water. All reagents were high purity, $99.99 \%$ or better, from Sigma Aldrich, except for $\mathrm{HI}_{67}$ which was obtained from Fluka. Immediately after being made up the solutions were homogenised by agitating for five minutes.

We estimate that the compositions of the mixtures were fixed to better than $0.01 \mathrm{wt} \%$ by this process. However, uncertainties in $\mathrm{HI}$ and $\mathrm{I}_{2}$ concentrations are larger than $0.01 \mathrm{wt} \%$ as a consequence of the uncertainty in the $\mathrm{wt} \%$ of $\mathrm{HI}$ present in the $\mathrm{HI}_{57}$ and $\mathrm{HI}_{67}$ stock solutions and the action of unspecified oxidation processes which slowly releases $\mathrm{I}_{2}$ in these solutions. To avoid using chemically stabilised $\mathrm{HI}$ stock solutions the $\mathrm{I}_{2}$ and $\mathrm{HI}$ wt $\%$ in $\mathrm{HI}_{57}$ and $\mathrm{HI}_{67}$ were determined immediately prior to use by titration against sodium thiosulfate and sodium hydroxide, respectively. The uncertainties in the $\mathrm{HI}$ and $\mathrm{I}_{2}$ compositions of prepared samples are effectively proportional to $x_{\mathrm{HI}}$, and have a maximum of $0.5 \mathrm{wt} \%$ in $\mathrm{HI}_{67}$.

The stoichiometric $\mathrm{HI}$ mole fractions $\left(x_{\mathrm{HI}}\right)$ in $\mathrm{HI}_{57}$ and $\mathrm{HI}_{67}$ are 0.157 and 0.222 , respectively, and a wide range of $\mathrm{HI}-\mathrm{I}_{2}-\mathrm{H}_{2} \mathrm{O}$ samples could be prepared conveniently by simply adding $\mathrm{I}_{2}$ and $\mathrm{H}_{2} \mathrm{O}$ to one or other of these $\mathrm{HI}$ solutions. The range of $x_{\mathrm{HI}}$ accessible by dilution in this way is to the low $x_{\mathrm{HI}}$ side of the boundary line given by the relation: $x_{\mathrm{H}_{2} \mathrm{O}}=0.78\left(1-x_{\mathrm{I}_{2}}\right)$. The ternary solutions with $\mathrm{KI}$ could be prepared with $x_{\mathrm{KI}}$ values larger than the limiting values possible for $x_{\mathrm{HI}}$.

The homogenised systems were sealed within customized quartz cells, described elsewhere [20].

The quartz cells were used both in the SRS measurements performed at room temperature, $298 \mathrm{~K}$, and the INS measurements performed at $20 \mathrm{~K}$.

2.1. Sample Composition. The compositions of the samples investigated in this study, together with details of the respective measurement conditions, are given in Table 1 and represented graphically on the suitably truncated room temperature $\mathrm{HI}-\mathrm{I}_{2}-\mathrm{H}_{2} \mathrm{O}$ ternary phase diagram shown in Figure 3 (N.B. the KI contents of samples S10 and S11 are shown using the HI scale). The compositions of the samples were distributed throughout the region of interest in the phase diagram (see Section 1) with the additional constraint that all compositions of the $\mathrm{HI}-\mathrm{I}_{2}-\mathrm{H}_{2} \mathrm{O}$ system were within the region that is liquid at room temperature, that is, to the right of the phase boundary (shown as green dashed line in Figure 1), whereas the samples of the $\mathrm{KI}-\mathrm{I}_{2}-\mathrm{H}_{2} \mathrm{O}$ system lie on the edge of the liquid phase boundaries described elsewhere [21].

2.2. Spontaneous Raman Scattering (SRS) Measurements. Dispersive Raman measurements were made using a Renishaw RM1000 Raman microscope and a Renishaw Ramascope System 2000 spectrometer equipped, respectively, with 514.5 and $785 \mathrm{~nm}$ excitation lasers. Raman spectra in the 
TABLE 1: The compositions of samples used in this study together with details of the excitation wavelength used.

\begin{tabular}{lccccc}
\hline Sample & $x_{\mathrm{HI}}$ & $x_{\mathrm{KI}}$ & $x_{\mathrm{I}_{2}}$ & $x_{\mathrm{H}_{2} \mathrm{O}}$ & Excitation $\lambda / \mathrm{nm}$ \\
\hline S1 & 0.157 & - & 0.000 & 0.843 & $514.5 ; 785$ \\
S2 & 0.222 & - & 0.000 & 0.778 & $514.5 ; 785$ \\
S3 & 0.170 & - & 0.079 & 0.751 & 514.5 \\
S4 & 0.196 & - & 0.100 & 0.704 & 514.5 \\
S5 & 0.118 & - & 0.076 & 0.806 & 514.5 \\
S6 & 0.187 & - & 0.159 & 0.654 & 514.5 \\
S7 & 0.115 & - & 0.180 & 0.705 & 514.5 \\
S8 & 0.154 & - & 0.307 & 0.539 & 514.5 \\
S9 & 0.118 & - & 0.249 & 0.633 & 514.5 \\
S10 & - & 0.199 & 0.200 & 0.601 & 514.5 \\
S11 & - & 0.153 & 0.276 & 0.571 & 514.5 \\
\hline
\end{tabular}

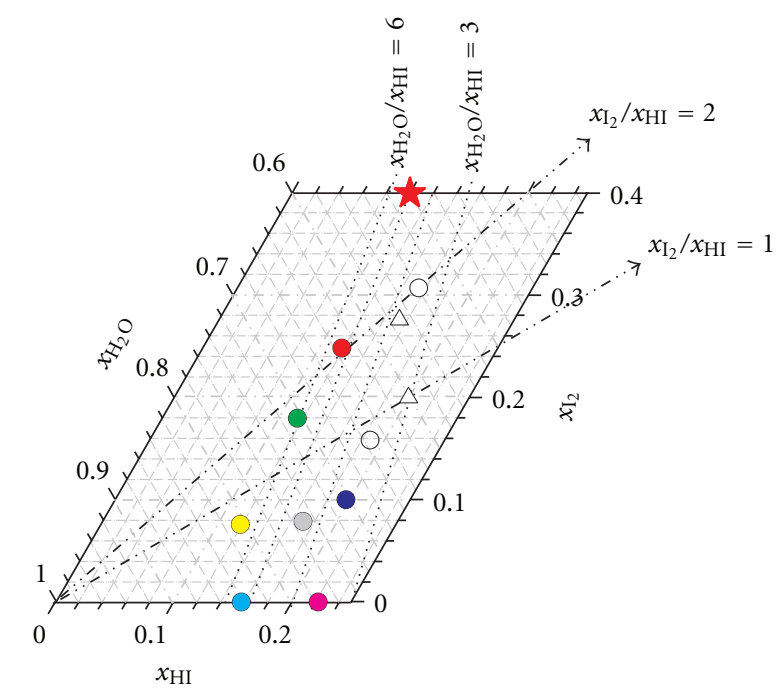

Figure 3: Sample compositions at $298 \mathrm{~K}$ placed on diagram shown in Figure 2. Circles represent samples of the HI- $\mathrm{I}_{2}-\mathrm{H}_{2} \mathrm{O}$ system; whereas triangles correspond to samples of the $\mathrm{KI}-\mathrm{I}_{2}-\mathrm{H}_{2} \mathrm{O}$ system.

region from 20 to $400 \mathrm{~cm}^{-1}$, important in measurements of condensed phase $\mathrm{I}_{2}$-containing species, were obtained using a near excitation tunable (NExT) filter accessory for the RM1000 instrument, use of which precludes measurement of the depolarization ratios of Raman active bands. Raman spectra in the region from 200 to $4000 \mathrm{~cm}^{-1}$ were obtained using the two spectrometers with their respective notch holographic filters. On both instruments, Raman spectra were measured in the backscattering configuration using incident laser powers of a few $10 \mathrm{~s} \mathrm{mW.} \mathrm{For} \mathrm{NExT} \mathrm{measurements} \mathrm{the}$ RM1000 instrument was used in static scan mode, with a slit width of $5 \mu \mathrm{m}$ and a $20 \mathrm{x}$ objective lens. Typical exposure times were $60 \mathrm{~s}$, with 60 accumulations being made per sample. For notch mode measurements the instruments were used in extended scan mode, with a slit width of $15 \mu \mathrm{m}$ and a 20x objective lens. Typical exposure times were $10 \mathrm{~s}$ for the RM1000 and $0.1 \mathrm{~s}$ for the Ramascope 2000, with between 10 and 30 accumulations being made per sample depending on the scattering strength of the sample.
Raman shift calibrations were performed at both the beginning and end of each measurement session using the $520.0 \mathrm{~cm}^{-1}$ resonance from a silicon wafer sample.

A Raman microscope accessory made it possible to perform excitation and scattered light collection normal to the flat face of a vertically oriented cell. The temperature of the samples during the measurements using $514.5 \mathrm{~nm}$ excitation was close to $298 \mathrm{~K}$; the temperature of the two samples measured using $785 \mathrm{~nm}$ excitation was not as closely monitored but was similar.

2.3. Inelastic Neutron Scattering (INS) Measurements. The INS measurements were performed on samples maintained at $20 \mathrm{~K}$ after they had been initially quenched in a cryostat operating at about $50 \mathrm{~K}$. The dosed cells were mounted in the neutron beam of the TOSCA spectrometer [22, 23], at the ISIS Facility, at Rutherford Appleton Laboratory. TOSCA is a pulsed neutron, indirect geometry, low bandpass spectrometer with good spectral resolution $\left(\Delta E_{t} / E_{t} \approx\right.$ $2 \%)[22,23]$. Spectral data were collected for approximately six hours and transformed into conventional scattering law versus energy transfer $E_{t} / \mathrm{cm}^{-1}$, using standard programs. The resulting INS spectra appear noisy in comparison to the Raman spectra obtained from the same samples (see below) because typical neutron fluxes are about ten orders of magnitude less than photon flux from lasers.

2.4. Description of the Working Model Systems. In order to gain some insight into the interpretation of the INS spectra, four working models, $4 \mathrm{w}_{\mathrm{I}}$ (based on a geometry

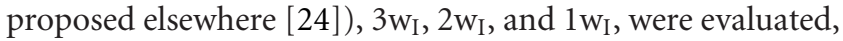
two of which were assumed to explain the molecular dynamics of the $\mathrm{HI}-\mathrm{H}_{2} \mathrm{O}$ and the $\mathrm{HI}-\mathrm{I}_{2}-\mathrm{H}_{2} \mathrm{O}$ systems. Both models are idealised conceptions, since all interactions with their surroundings are neglected (isolated model), and the complicating influence of the abovementioned $\mathrm{I}_{2}$-containing species was reduced by considering only one iodine atom within the negatively charged aquo-complexes.

The first model, $4 \mathrm{w}_{\mathrm{I}}$, is a water tetramer coupled to an iodide ion, see Figure 4, classified within the $C_{4}$ point group, It shows 33 fundamental modes, which are distributed as follows: $\Gamma_{\mathrm{vib}}=8 A+9 B+16 E$. The other model, $3 \mathrm{w}_{\mathrm{I}}$, is a water trimer with an associated central iodide ion, see Figure 4, with $C_{3}$ symmetry, and 24 fundamental modes: $\Gamma_{\text {vib }}=8 A+$ $16 E$. Particular labelling for each water molecule, as well as description of the vibrational modes has been partially based on work reported elsewhere [25].

2.5. Computational Chemistry Calculations. The optimized geometries as well as vibrational frequencies of the putative structure of the aquo-complexes were calculated in GAUSSIAN 03 [26], using the second-order Moller-Plesset Perturbation Theory, MP2 computational method [27], which explicitly accounts for dispersion effects, important in the description of hydrogen bonding. The Stuttgart small core pseudorelativistic effective core potential [28] with 25 valence electrons was employed for iodine. The ECP was used with the valence triple- $f$ plus one polarization type 

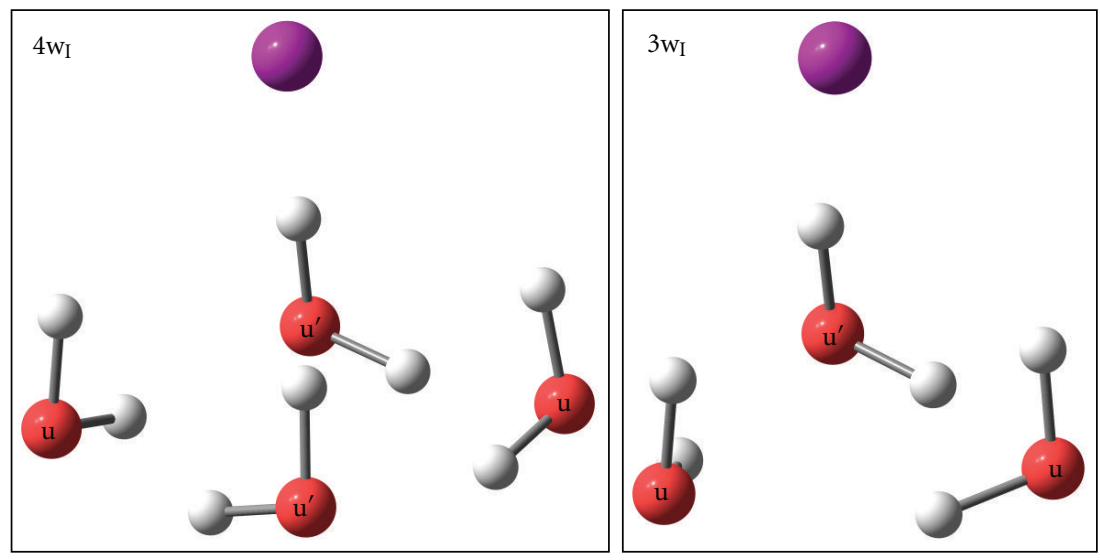

FIGURE 4: Optimized geometries of the working models $4 \mathrm{w}_{\mathrm{I}}$ and $3 \mathrm{w}_{\mathrm{I}}$. Water molecules within the complexes are labelled to ease description of the vibrational modes.
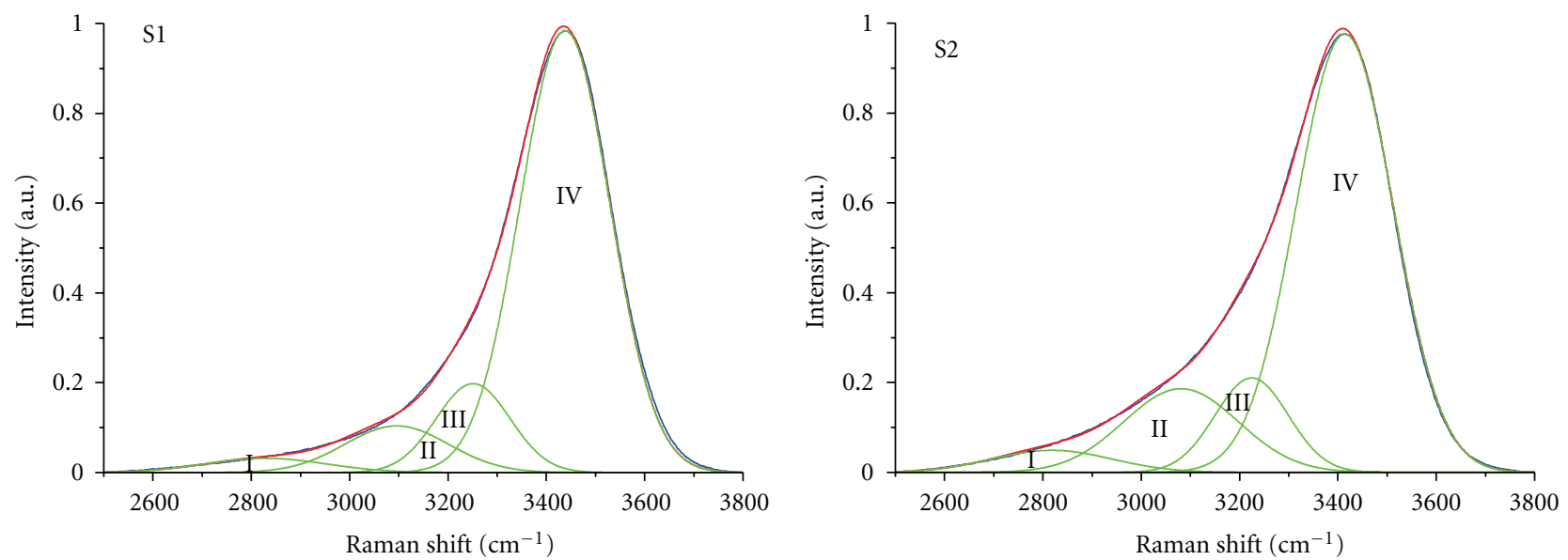

FIGURE 5: Raman spectra, within the region from $2500 \mathrm{~cm}^{-1}$ to $3800 \mathrm{~cm}^{-1}$, of samples S1 and S2 taken using $514.5 \mathrm{~nm}$ excitation at $298 \mathrm{~K}$ and shown on a common intensity scale normalised to the most intense feature in each spectrum.

(TZVP), which is an optimized contracted Gaussian basis set for iodine, calculated by Schäfer et al. [29]. In the case of hydrogen and oxygen, the TZVP basis set was used $[29,30]$. The final output files from the calculations, which contain the eigenvalues and eigenvectors, were processed in ACLIMAX [31] to generate calculated INS spectra for comparison with observed spectra from TOSCA.

\section{Results and Discussion}

\subsection{The Binary System: $\mathrm{HI}-\mathrm{H}_{2} \mathrm{O}$}

3.1.1. $2,800-3,800 \mathrm{~cm}^{-1}$ Region. SRS is known to provide useful information in this region in contrast to TOSCA where its high momentum transfer results in the suppression of intensities and only indistinct spectra are observed.

The two samples of the $\mathrm{HI}-\mathrm{H}_{2} \mathrm{O}$ binary system, S1 $\left(x_{\mathrm{H}_{2} \mathrm{O}} / x_{\mathrm{HI}}=5.4\right)$ and $\mathrm{S} 2\left(x_{\mathrm{H}_{2} \mathrm{O}} / x_{\mathrm{HI}}=3.5\right)$ showed strong features in their $514.5 \mathrm{~nm}$ excitation SRS spectra in the $\mathrm{OH}$ stretch region from 2,800 to $3,800 \mathrm{~cm}^{-1}$. The compositions of these two samples are chosen specially: $\mathrm{S} 1$ is quite close to the actual azeotrope of the $\mathrm{HI}-\mathrm{H}_{2} \mathrm{O}$ system; $\mathrm{S} 2$ has the lowest $x_{\mathrm{H}_{2} \mathrm{O}} / x_{\mathrm{HI}}$ mole ratio feasible. This latter ratio is of particular interest since it has been observed that in other halide acids (i.e., $\mathrm{HCl}, \mathrm{HBr}$ ) a minimum of four water molecules is needed to stabilize ionic structures $[32,33]$.

The respective SRS spectra of each sample comprise a single, strong, asymmetric band with a maximum near $3,400 \mathrm{~cm}^{-1}$. The good quality of the spectra made it possible to fit four Gaussians to the observed profile leaving low fitting residuals. The fitting process was guided by former band analysis studies carried out on hydriodic acid solutions [12]. Thus in accordance with this study, four bands were fitted in each spectrum, as illustrated in Figure 5. The centre of gravity as well as relative intensity and full width at half maximum (FWHM) of each Gaussian component are given in Table 2.

Component Raman bands in this region have normally been associated with the dynamics of the local hydrogen bonding network, including hydroxonium interactions. Thus, in this work, band I and band II have been assigned to antisymmetric, $\nu_{3}$, and symmetric, $\nu_{1}$, stretching of the 


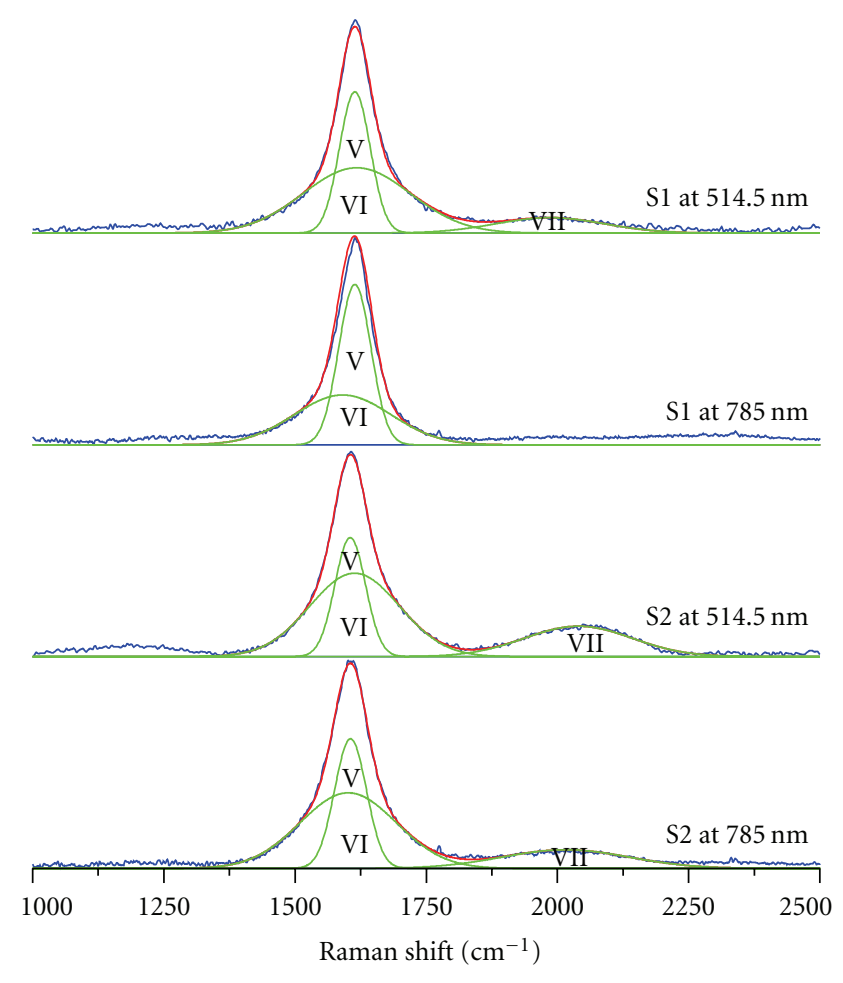

Figure 6: Raman spectra, within the region from $1000 \mathrm{~cm}^{-1}$ to $2500 \mathrm{~cm}^{-1}$, of samples S1 and S2 taken at $298 \mathrm{~K}$ using excitation sources of $514.5 \mathrm{~nm}$ and $785 \mathrm{~nm}$.
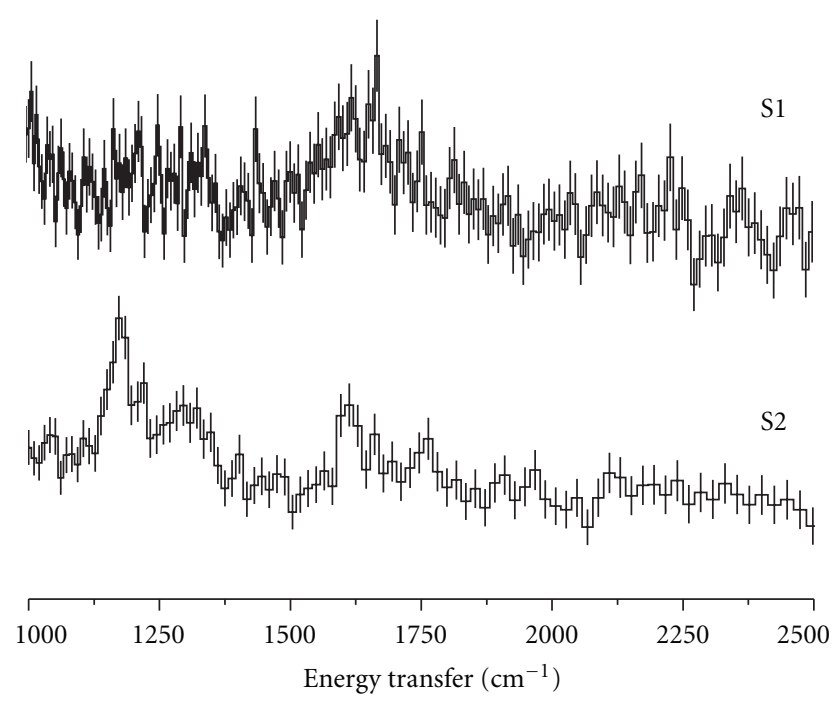

Figure 7: INS spectra, within the region from $1000 \mathrm{~cm}^{-1}$ to $2500 \mathrm{~cm}^{-1}$, of samples S1 and S2 taken at $20 \mathrm{~K}$. Vertical lines along the INS spectra represent error bars.

hydroxonium ions $\left(\mathrm{H}_{3} \mathrm{O}^{+}\right)$, in agreement with previous studies $[8,34]$. Both bands showed an enhancement in S2, revealing a higher hydroxonium concentration in this system. Typically, hydroxonium ions are not observed in the bulk of dilute solutions of hydriodic acid. The hydroxonium ions are a defect within the hydrogen bonding network, and are usually forced to the surface, where they have been detected

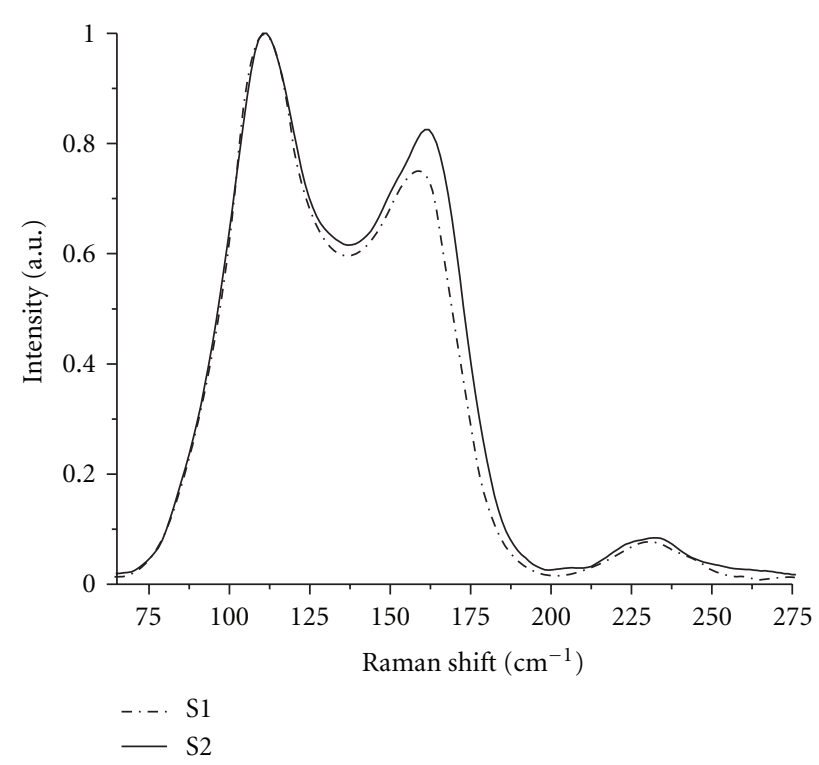

Figure 8: Raman spectra, within the region from $50 \mathrm{~cm}^{-1}$ to $275 \mathrm{~cm}^{-1}$, of samples S1 and S2 taken using $514.5 \mathrm{~nm}$ excitation at $298 \mathrm{~K}$ and shown on a common intensity scale normalised to the most intense feature in each spectrum.

[35]. Here, however, probably in the case of S1, but almost certainly in the case of S2, the limited number of water molecules produces hydroxonium ions within the bulk of the local hydrogen bonding network, where they are detected. Support for the occurrence of hydroxonium ions in the bulk can be found in recent simulations, which revealed the existence of these bulk ions in $1 \mathrm{M}$ hydriodic acid solutions [36].

On the other hand, bands III and IV are more closely related to the water's hydrogen bonding network. Thus, band III has been attributed to bulk amorphous water [37], more specifically to $\nu_{1}$ of water molecules exhibiting a tetrahedral configuration [12,38]. Band IV has been assigned to $\nu_{3}$ of those water molecules associated with the iodide hydration shell $[12,38]$. This band displays an important intensity enhancement in S2, (this is not obvious from Figure 5 due to spectral normalization). Such intensity increase is clearly due to the increased polarizability of those water molecules forming the iodide solvation sphere. In the S2 sample, with its relatively smaller number of water molecules, most of them will be in hydration spheres [38]. Band IV is assigned according to the "Rull" model [17] and is dominated by contributions from the linear $\mathrm{H}$-bond of the $\mathrm{OH} \cdots \mathrm{I}$ solvation complex rather than the bifurcated or interstitial H-bond.

\subsection{2. $1,000-2,500 \mathrm{~cm}^{-1}$ Region}

SRS Spectra. The SRS spectra of this region, collected with two different excitation sources, have been analysed. The resultant component bands are shown in Figure 6, and their details are summarised in Table 3. 
TABLE 2: Bands recovered by deconvolution of the Raman spectra obtained from samples of the $\mathrm{HI}-\mathrm{H}_{2} \mathrm{O}$ binary system (S1, S2) at 298 K and $514.5 \mathrm{~nm}$ in the spectral region $2800-3800 \mathrm{~cm}^{-1}$. The entries for each band in this and subsequent tables, (from left to right) comprise band position; (within brackets) relative intensity normalized to the most intense band in each spectrum; (within brackets in italics) and bandwidth. Additionally the final column shows the $x_{\mathrm{H}_{2} \mathrm{O}} / x_{\mathrm{HI}}$ mole ratio.

\begin{tabular}{lcccc}
\hline Sample & Band I $/ \mathrm{cm}^{-1}$ & Band II $/ \mathrm{cm}^{-1}$ & Band III $/ \mathrm{cm}^{-1}$ & ${\mathrm{Band} \mathrm{IV} / \mathrm{cm}^{-1}}^{\mathrm{x}_{\mathrm{H}_{2} \mathrm{O}} / \mathrm{x}_{\mathrm{HI}}}$ \\
\hline S1 & $2829(0.04 ; 289.2)$ & $3096(0.12 ; 248.8)$ & $3251(0.16 ; 177.3)$ & $3438(1.00 ; 216.1)$ \\
S2 & $2818(0.06 ; 286.4)$ & $3081(0.22 ; 274.1)$ & $3225(0.16 ; 175.4)$ & $3414(1.00 ; 232.9)$ \\
\hline
\end{tabular}

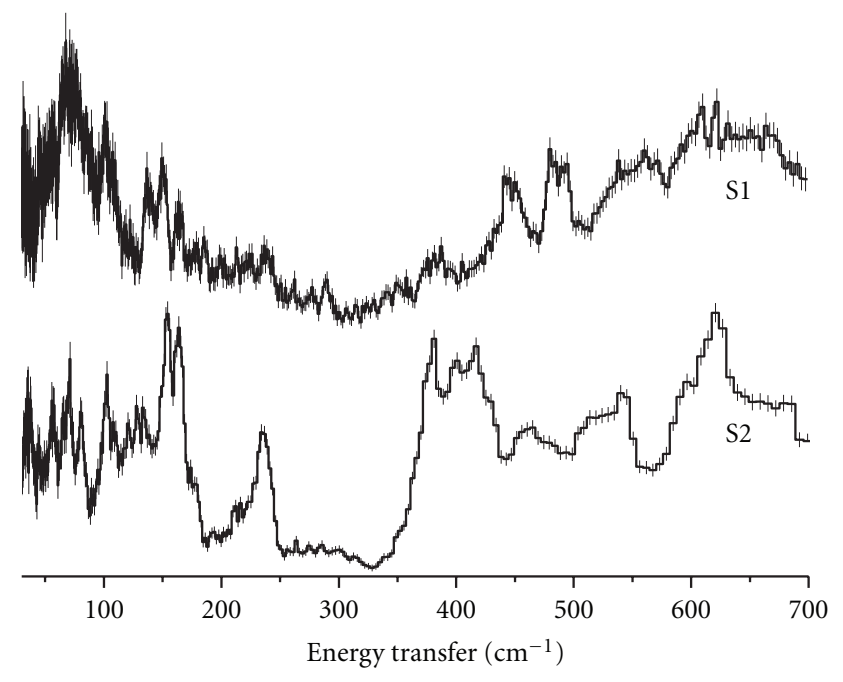

FIGURE 9: INS spectra, within the region from $30 \mathrm{~cm}^{-1}$ to $700 \mathrm{~cm}^{-1}$, of samples S1 and S2 taken at $20 \mathrm{~K}$.

The strong, asymmetric feature at $c a .1600 \mathrm{~cm}^{-1}$ is usually associated with the water bending mode, $v_{2}$, and has been decomposed into two component bands $[39,40]$, one sharp, the other broad. In agreement with this early work, band $\mathrm{V}$ is attributed to the $\nu_{2}$ of water molecules exhibiting tetrahedral configuration and band VI has been assigned to $\nu_{2}$ of water molecules linked to iodide ion solvation shells. Support for these assignments is the noticeable shift of band VI to higher wavenumbers, as the excitation wavelength approaches the absorption of the complex ion $\mathrm{OH} \cdots \mathrm{I}$. Band V has a constant centre of gravity irrespective of the excitation wavelength.

The SRS spectra in Figure 6 also show the presence of a seventh broad band at $c a .2000 \mathrm{~cm}^{-1}$, band VII. This band demonstrates a resonance enhancement (it is strong in S2, with $514.5 \mathrm{~nm}$, but is inactive in S1, with $785 \mathrm{~nm}$ ) and a clear dependence on $\mathrm{HI}$ concentration. Rather than assigning band VII to a water combination band (e.g., $v_{2}+\nu_{L}$ ), it is more reasonable to assign it to $\mathrm{H}_{2} \mathrm{O} \cdots \mathrm{HI}$ complexes. Earlier Raman studies on supersaturated solutions of other hydrogen halides [41] suggest that a Raman feature near $2040 \mathrm{~cm}^{-1}$ would be present in highly concentrated hydriodic acid.

INS Spectra. INS spectra of the same spectral region, see Figure 7, also show bands V and VI at $c a .1600 \mathrm{~cm}^{-1}$ in both S1 and S2, although broader in S1. Exclusively observed in the INS spectrum of S2, is a band at $c a .1170 \mathrm{~cm}^{-1}$.
Hydroxonium ions may account for this band; since their detection is clearly eased by the low temperature, $20 \mathrm{~K}$, at which measurements were carried out that greatly suppresses proton diffusion [42]. Moreover, the concentration of S2, $10.27 \mathrm{M}$, is above the concentration threshold, $>7 \mathrm{M}$, established for the observation of the ion's symmetric bending mode, $v_{2}$, in hydrogen halide solutions [8].

Given this assignment, it is possible that the band at ca. $1600 \mathrm{~cm}^{-1}$ in $\mathrm{S} 2$ might have a different origin from that presented above. Under this interpretation, with the extinction of band V, the two well-defined peaks at $c a .1613$ and $1750 \mathrm{~cm}^{-1}$ would then be assigned to band VI and the antisymmetric bending mode, $v_{4}$, of the hydroxonium ion.

\subsection{3. $30-700 \mathrm{~cm}^{-1}$ Region}

SRS Spectra. The SRS spectra obtained using the notch filter show only two weak, semiobscured, bands at $c a .330 \mathrm{~cm}^{-1}$ and $480 \mathrm{~cm}^{-1}$ under $514.5 \mathrm{~nm}$ excitation. These are overtone progressions and combinations resulting from a resonance enhancement, discussed below.

More useful SRS spectra were acquired using the NExT Filter at $514.5 \mathrm{~nm}$ and these are shown in Figure 8. An SRS study of these systems in this region has recently been reported and discussed in detail by our research group and they are only briefly summarised here [14].

One very weak Raman band $c a .85 \mathrm{~cm}^{-1}$ and another five bands are located at $c a .111,137,160,230$, and $337 \mathrm{~cm}^{-1}$ and can all be attributed to $\mathrm{I}_{2}$-containing species.

Specifically, all bands except for the band $c a .160 \mathrm{~cm}^{-1}$ somehow derive from an $\mathrm{I}_{3}{ }^{-}$species with equidistant bonds whereas the band at $c a .160 \mathrm{~cm}^{-1}$ represents only an $\mathrm{I}_{2}$ grouping within an unsymmetric $\mathrm{I}_{3}{ }^{-}$. The structure of the $\mathrm{I}_{3}{ }^{-}$ ion responsible for this band can be represented as $\mathrm{I}^{-}\left(\mathrm{I}_{2}\right)$.

The bands overall located $c a .111,230$, and $337 \mathrm{~cm}^{-1}$ are assigned to the symmetric stretch, the fundamental at $c a$. $111 \mathrm{~cm}^{-1}$, and its first and second overtones at $c a .230$ and $337 \mathrm{~cm}^{-1}$, respectively. The bands at $c a .85$ and $137 \mathrm{~cm}^{-1}$ are the bending and antisymmetric stretching modes of symmetric $\mathrm{I}_{3}{ }^{-}$. At first glance the assignment of the overtone series might seem dubious, since it does not seem to fit with the anharmonic oscillator model. However, we have recently demonstrated the attenuation of these two overtones changing the excitation frequency off resonance to $1064 \mathrm{~nm}$ [14]. Furthermore, Kiefer and Bernstein [43] also reported similar band positions for $\mathrm{CsI}_{3}$ in aqueous solution, which are in close agreement with our assignment. 
TABLE 3: The Raman bands recovered by deconvolution of the spectra obtained from samples of the HI- $\mathrm{H}_{2} \mathrm{O}$ binary system (S1, S2) at 298 K in the spectral region $1000-2500 \mathrm{~cm}^{-1}$. Results in bold were obtained at $514.5 \mathrm{~nm}$, whereas the rest were acquired at $785 \mathrm{~nm}$.

\begin{tabular}{|c|c|c|c|c|}
\hline Sample & Band $\mathrm{V} / \mathrm{cm}^{-1}$ & Band VI $/ \mathrm{cm}^{-1}$ & Band VII $/ \mathrm{cm}^{-1}$ & $\mathrm{x}_{\mathrm{H}_{2} \mathrm{O}} / \mathrm{x}_{\mathrm{HI}}$ \\
\hline \multirow{2}{*}{$\mathrm{S} 1$} & $1614(0.62 ; 68.9)$ & $1617(1.00 ; 240.8)$ & $1986(0.24 ; 242.7)$ & \multirow{2}{*}{5.4} \\
\hline & $1614(1.00 ; 72.3)$ & $1591(0.93 ; 216.6)$ & - & \\
\hline \multirow{2}{*}{ S2 } & $1605(0.49 ; 68.6)$ & $1613(1.00 ; 201.1)$ & $2040(0.44 ; 241.4)$ & \multirow{2}{*}{3.5} \\
\hline & $1606(0.57 ; 71.4)$. & $1601(1.00 ; 215.3)$ & $2015(0.33 ; 285.0)$ & \\
\hline
\end{tabular}

TABLE 4: Calculated vibrational modes of $4 \mathrm{w}_{\mathrm{I}}$ together with their individual descriptions. Mode description: $\mathrm{H}_{\mathrm{b}}$ and $\mathrm{H}_{\mathrm{f}}$ refer to hydrogen atoms within the water molecules that are hydrogen bonded or free, respectively; superscripts $\mathrm{n}$ and nc stand for concerted and nonconcerted motion respectively; $\nu_{3}$ for antisymmetric stretch; $\nu_{1}$ for symmetric stretch; $\nu_{2}$ for bending mode; $\omega$ for wag; $\rho$ for rock; $\tau$ for twist; / used to separate concerted motions from nonconcerted motions. Modes descriptions in bold font highlight the normal modes of water. Compression, distortion, and twist modes refer to the tetramer ring, except for those in italics which refer to motions of the whole complex.

\begin{tabular}{|c|c|c|c|c|c|c|c|c|}
\hline $4 \mathrm{w}_{\mathrm{I}}\left(C_{4}\right)$ & $\Gamma_{\mathrm{vib}}=$ & $+9 B+16 E$ & & & & & & \\
\hline $\begin{array}{l}\nu \\
A\end{array}$ & $\begin{array}{l}\text { Calculated } \\
\left(\mathrm{cm}^{-1}\right)\end{array}$ & Description & $\begin{array}{l}v \\
B\end{array}$ & $\begin{array}{c}\text { Calculated } \\
\left(\mathrm{cm}^{-1}\right)\end{array}$ & Description & $\begin{array}{l}\nu \\
E\end{array}$ & $\begin{array}{c}\text { Calculated } \\
\left(\mathrm{cm}^{-1}\right)\end{array}$ & Description \\
\hline 1 & 3796 & $\boldsymbol{v}_{3}^{\mathrm{c}}\left(\mathbf{u} \mathbf{u}^{\prime} \mathbf{u} \mathbf{u}^{\prime}\right)$ & 9 & 3760 & $\nu_{3}{ }^{\mathrm{nc}}\left(\mathbf{u u} / \mathbf{u}^{\prime} \mathbf{u}^{\prime}\right)$ & 18 & \multirow{2}{*}{3771} & $\nu_{3}{ }^{\mathrm{nc}}\left(\mathbf{u}^{\prime} \mathbf{u} / \mathbf{u}^{\prime} \mathbf{u}\right)$ \\
\hline 2 & 3627 & $\nu_{1}^{c}\left(\mathbf{u u}^{\prime} \mathbf{u u}^{\prime}\right)$ & 10 & 3704 & $\boldsymbol{v}_{\mathbf{1}}^{\mathrm{nc}}\left(\mathbf{u}^{\prime} \mathbf{u} \mathbf{u}^{\prime} \mathbf{u}\right)$ & 19 & & $\nu_{3}{ }^{\mathrm{nc}}\left(\mathbf{u u}^{\prime} / \mathbf{u u}^{\prime}\right)$ \\
\hline 3 & 1712 & $\nu_{2}^{c}\left(u^{\prime} \mathbf{u u} u^{\prime}\right)$ & 11 & 1718 & $\nu_{2}{ }^{\mathrm{nc}}\left(\mathbf{u}^{\prime} \mathbf{u} / \mathbf{u}^{\prime} \mathbf{u}\right)$ & 20 & \multirow{2}{*}{3674} & $\nu_{1}{ }^{n c}\left(\mathbf{u}^{\prime} \mathbf{u} / \mathbf{u}^{\prime} \mathbf{u}\right)$ \\
\hline 4 & 925 & $\omega^{\mathrm{c}}\left(\mathrm{H}_{\mathrm{b}} \mathrm{uu}^{\prime} u u^{\prime}\right)$ & 12 & 586 & $\omega^{\mathrm{nc}}\left(\mathrm{H}_{b} \mathrm{uu} / \mathrm{u}^{\prime} \mathrm{u}^{\prime}\right)$ & 21 & & $\nu_{1}{ }^{n c}\left(u^{\prime} / u^{\prime}\right)$ \\
\hline 5 & 625 & $\rho^{\mathrm{c}}\left(\mathrm{uu}^{\prime} \mathrm{uu}^{\prime}\right)$ & 13 & 465 & $\tau^{\mathrm{nc}}\left(\mathrm{uu} / \mathrm{u}^{\prime} \mathrm{u}^{\prime}\right)$ & 22 & \multirow{2}{*}{1707} & $\nu_{2}{ }^{\mathrm{nc}}\left(\mathbf{u u ^ { \prime }} / \mathbf{u} \mathbf{u}^{\prime}\right)$ \\
\hline 6 & 379 & $\tau^{\mathfrak{c}}\left(\mathrm{H}_{\mathrm{f}} \mathrm{uu}^{\prime} \mathrm{uu}^{\prime}\right)$ & 14 & 377 & $\rho^{\mathrm{nc}}\left(\mathrm{uu} / \mathrm{u}^{\prime} \mathrm{u}^{\prime}\right)$ & 23 & & $\boldsymbol{v}_{2}{ }^{\mathrm{nc}}\left(\mathbf{u}^{\prime} \mathbf{u} / \mathbf{u}^{\prime} \mathbf{u}\right)$ \\
\hline 7 & 169 & Compression & 15 & 201 & Distortion & 24 & \multirow{2}{*}{723} & $\omega^{\mathrm{nc}}\left(\mathrm{H}_{\mathrm{b}} \mathrm{u}^{\prime} \mathrm{u} / \mathrm{u}^{\prime} \mathrm{u}\right)$ \\
\hline 8 & 91 & Compression & 16 & 89 & Twist & 25 & & $\omega^{\mathrm{nc}}\left(\mathrm{H}_{\mathrm{b}} \mathrm{uu}^{\prime} / \mathrm{uu}^{\prime}\right)$ \\
\hline & & & 17 & 59 & Distortion & 26 & \multirow{2}{*}{559} & $\tau^{\mathrm{nc}}\left(\mathrm{H}_{\mathrm{b}} \mathrm{u}^{\prime} \mathrm{u} / \mathrm{u}^{\prime} \mathrm{u}\right)$ \\
\hline & & & & & & 27 & & $\tau^{\mathrm{nc}}\left(\mathrm{H}_{\mathrm{b}} \mathrm{uu}^{\prime} / \mathrm{uu}^{\prime}\right)$ \\
\hline & & & & & & 28 & \multirow{2}{*}{362} & $\rho^{\mathrm{nc}}\left(\mathrm{H}_{\mathrm{f}} \mathrm{u}^{\prime} \mathrm{u} / \mathrm{u}^{\prime} \mathrm{u}\right)$ \\
\hline & & & & & & 29 & & $\rho^{\mathrm{nc}}\left(\mathrm{H}_{\mathrm{f}} \mathrm{uu}^{\prime} / \mathrm{uu}^{\prime}\right)$ \\
\hline & & & & & & 30 & \multirow{2}{*}{189} & Distortion \\
\hline & & & & & & 31 & & Distortion \\
\hline & & & & & & 32 & \multirow{2}{*}{88} & Rocking \\
\hline & & & & & & 33 & & Rocking \\
\hline
\end{tabular}

INS Spectra. In contrast to SRS spectra the INS spectra in this region are very rich in features, see Figure 9. This apparent contradiction is easily resolved when it is realized that SRS spectra give information on the $\mathrm{I}_{2}$-containing species present and INS gives information on the hydrogenous species present. INS provides information about the water surrounding the iodide complex ions in this system.

It is also worth underlining that samples studied on TOSCA reach $273 \mathrm{~K}$ within $5 \mathrm{~s}$ and once frozen no significant structural differences are expected. Glass formation can be inferred in samples of the binary system, given that $\mathrm{HCl}$ and $\mathrm{HBr}$ form glasses at concentrations higher than $20 \mathrm{wt} \%$ and $30 \mathrm{wt} \%$ respectively [42].

We shall assume that there are two contributors to the observed INS spectral profile, first, free water molecules in a tetrahedral hydrogen bonding network (as found in pure water), and, second, water molecules taking part in the ionic solvation shells. The INS spectrum of S1 is then seen to be due to the presence of both species and that of S2 is dominated by the water envelope of the iodide ions.
This is approximately in line with simple expectations based on the mole ratio of water to HI. We recall that previous studies suggested that at least 4 water molecules are needed to stabilize iodide ions $[15,35]$. Then, in S1 there is an excess of water molecules $\left(x_{\mathrm{H}_{2} \mathrm{O}} / x_{\mathrm{HI}}=5.4\right)$ but in $\mathrm{S} 2$ a deficit $\left(x_{\mathrm{H}_{2} \mathrm{O}} / x_{\mathrm{HI}}=3.5\right)$. The INS of S2 is sharply featured and convincingly fits expectations from a locally structured system like a hydration shell. The INS spectrum of S1 is more diffuse and best compared to that of water in its more "open" ice structures [18]. Here we note that our systems, although locally ordered, show no long-range order, as demonstrated by the lack of Bragg features in the diffraction bank of TOSCA.

Here, we recall that our interpretation of the INS spectra will be through the two model systems, $4 \mathrm{w}_{\mathrm{I}}$ and $3 \mathrm{w}_{\mathrm{I}}$, discussed above. In this respect, Tables 4 and 5 show the unscaled calculated frequencies obtained for the working models $4 \mathrm{w}_{\mathrm{I}}$ and $3 \mathrm{w}_{\mathrm{I}}$.

We have proposed the above working models based on the fact that there is insufficient water $\left(x_{\mathrm{H}_{2} \mathrm{O}} / x_{\mathrm{HI}}=3.5\right)$ to 
TABLE 5: Calculated vibrational modes of $3 \mathrm{w}_{\mathrm{I}}$ together with their individual descriptions. Compression, distortion, and twist modes refer to the trimer ring, except for those in italics which refer to motions of the whole complex.

\begin{tabular}{|c|c|c|c|c|c|}
\hline $3 \mathrm{w}_{\mathrm{I}}\left(C_{3}\right)$ & $\Gamma_{\mathrm{vib}}=$ & $8 A+16 E$ & & & \\
\hline $\begin{array}{l}v \\
A\end{array}$ & $\begin{array}{c}\text { Calculated } \\
\left(\mathrm{cm}^{-1}\right)\end{array}$ & Description & $\begin{array}{l}v \\
E\end{array}$ & $\begin{array}{c}\text { Calculated } \\
\left(\mathrm{cm}^{-1}\right)\end{array}$ & Description \\
\hline 1 & 3711 & $\nu_{3}^{c}\left(\mathbf{u u}^{\prime} \mathbf{u}\right)$ & 9 & \multirow{2}{*}{3789} & $\nu_{3}{ }^{\mathrm{nc}}\left(\mathbf{u}^{\prime} \mathbf{u} / \mathbf{u}\right)$ \\
\hline 2 & 3705 & $\nu_{1}^{c}\left(\mathbf{u u}^{\prime} \mathbf{u}\right)$ & 10 & & $\nu_{3}{ }^{\mathrm{nc}}\left(\mathbf{u u}^{\prime} / \mathbf{u}\right)$ \\
\hline 3 & 1712 & $\nu_{2}^{c}\left(\mathbf{u u}^{\prime} \mathbf{u}\right)$ & 11 & \multirow{2}{*}{3710} & $\nu_{1}{ }^{\mathrm{nc}}\left(\mathbf{u}^{\prime} \mathbf{u} / \mathbf{u}\right)$ \\
\hline 4 & 832 & $\omega^{\mathrm{c}}\left(\mathrm{H}_{\mathrm{b}} \mathrm{uu}^{\prime} \mathrm{u}\right)$ & 12 & & $v_{1}{ }^{\mathrm{nc}}\left(\mathbf{u u}^{\prime} / \mathbf{u}\right)$ \\
\hline 5 & 597 & $\tau^{\mathrm{c}}\left(\mathrm{H}_{\mathrm{f}} \mathrm{uu}^{\prime} \mathrm{u}\right)$ & 13 & \multirow{2}{*}{1687} & $\nu_{2}{ }^{\mathrm{nc}}\left(\mathbf{u u}^{\prime} / \mathbf{u}\right)$ \\
\hline 6 & 390 & $\rho^{\mathrm{c}}\left(\mathrm{uu}^{\prime} \mathrm{u}\right)$ & 14 & & $\nu_{2}{ }^{\mathrm{nc}}\left(\mathbf{u}^{\prime} \mathbf{u} / \mathbf{u}\right)$ \\
\hline 7 & 172 & Compression & 15 & \multirow{2}{*}{607} & $\omega^{\mathrm{nc}}\left(\mathrm{H}_{\mathrm{b}} \mathrm{u}^{\prime} \mathrm{u} / \mathrm{u}\right)$ \\
\hline 8 & 101 & Compression & 16 & & $\omega^{\mathrm{nc}}\left(\mathrm{H}_{\mathrm{b}} \mathrm{uu}^{\prime} / \mathrm{u}\right)$ \\
\hline & & & 17 & \multirow{2}{*}{462} & $\tau^{\mathrm{nc}}\left(\mathrm{H}_{\mathrm{b}} \mathrm{u}^{\prime} \mathrm{u} / \mathrm{u}\right)$ \\
\hline & & & 18 & & $\tau^{\mathrm{nc}}\left(\mathrm{H}_{\mathrm{b}} \mathrm{uu}^{\prime} / \mathrm{u}\right)$ \\
\hline & & & 19 & \multirow{2}{*}{343} & $\rho^{\mathrm{nc}}\left(\mathrm{H}_{\mathrm{f}} \mathrm{u}^{\prime} \mathrm{u} / \mathrm{u}\right)$ \\
\hline & & & 20 & & $\rho^{\mathrm{nc}}\left(\mathrm{H}_{\mathrm{f}} \mathrm{uu}^{\prime} / \mathrm{u}\right)$ \\
\hline & & & 21 & \multirow{2}{*}{150} & Distortion \\
\hline & & & 22 & & Distortion \\
\hline & & & 23 & \multirow{2}{*}{91} & Rocking \\
\hline & & & 24 & & Rocking \\
\hline
\end{tabular}

TABLE 6: Relevant mole ratios of the samples representative of the $\mathrm{HI}-\mathrm{I}_{2}-\mathrm{H}_{2} \mathrm{O}$ and $\mathrm{KI}-\mathrm{I}_{2}-\mathrm{H}_{2} \mathrm{O}$ ternary systems; which were used in this study.

\begin{tabular}{lcccc}
\hline Sample & $x_{\mathrm{I}_{2}} / x_{\mathrm{HI}}$ & $x_{\mathrm{I}_{2}} / x_{\mathrm{KI}}$ & $x_{\mathrm{H}_{2} \mathrm{O}} / x_{\mathrm{HI}}$ & $x_{\mathrm{H}_{2} \mathrm{O}} / x_{\mathrm{KI}}$ \\
\hline S3 & 0.46 & - & 4.4 & - \\
S4 & 0.51 & - & 3.6 & - \\
S5 & 0.64 & - & 6.8 & - \\
S6 & 0.85 & - & 3.5 & - \\
S7 & 1.57 & - & 6.2 & - \\
S8 & 2.00 & - & 3.5 & - \\
S9 & 2.10 & - & 5.4 & - \\
S10 & - & 1.00 & - & 3.0 \\
S11 & - & 1.81 & - & 3.7 \\
\hline
\end{tabular}

stabilize all the iodide ions directly. In terms of our model systems, this mole ratio is obtained when there is one $4 \mathrm{w}_{\mathrm{I}}$ unit to every $3 \mathrm{w}_{\mathrm{I}}$ unit. Thus we anticipate that in the case of S2 the hydrated iodide ion is present in both forms.

Figure 10 shows the calculated INS spectra, obtained from ACLIMAX, of both $4 \mathrm{w}_{\mathrm{I}}$ and $3 \mathrm{w}_{\mathrm{I}}$. When the calculated spectrum of the $3 \mathrm{w}_{\mathrm{I}}$ unit is added to a calculated spectrum of the $4 \mathrm{w}_{\mathrm{I}}$ unit the comparison between the calculated and observed spectra is convincing, as it can be observed in Figure 11. It is, thus, reasonable to accept that the INS spectrum of S2 results from equal contributions from similar structures to those already described above. Here, we do not mean to be understood as suggesting that the calculated spectrum is a "fit" to the observed data, as can often be the case with INS spectra [19]. Rather, that the vibrations of $4 \mathrm{w}_{\mathrm{I}}$ and $3 \mathrm{w}_{\mathrm{I}}$ provide an adequate representation of the observed spectrum and, by extension, the structural model encapsulates the essence of the local water structure in the sample.

It is noteworthy that although four working models, $4 \mathrm{w}_{\mathrm{I}}, 3 \mathrm{w}_{\mathrm{I}}, 2 \mathrm{w}_{\mathrm{I}}$, and $1 \mathrm{w}_{\mathrm{I}}$ were evaluated at first; only three of them resulted in stable geometries: $4 \mathrm{w}_{\mathrm{I}}, 3 \mathrm{w}_{\mathrm{I}}$, and $1 \mathrm{w}_{\mathrm{I}}$. In accordance with Odde et al., [15] it was found that $4 \mathrm{w}_{\mathrm{I}}$ and $3 \mathrm{w}_{\mathrm{I}}$ stabilized in ionic structures whereas $1 \mathrm{w}_{\mathrm{I}}$ behaved as an undissociated $\mathrm{HI}$-water cluster: $\mathrm{HI}\left(\mathrm{H}_{2} \mathrm{O}\right)$. Even though both $4 \mathrm{w}_{\mathrm{I}}$ and $3 \mathrm{w}_{\mathrm{I}}$ are stable moieties, it is well known that the former is more stable than the latter [15]. Thus, bearing all the above in mind, it is feasible to consider $1 \mathrm{w}_{\mathrm{I}}$ as responsible of some of the spectral features within the INS spectrum of S2. Indeed, Figure 12 juxtaposes the calculated INS spectrum of $1 w_{I}$ with the experimental data obtained at TOSCA. Such comparison, however, does not exhibit an agreement as significant as the one observed in Figure 11, particularly in the middle section, which in the actual spectrum is somehow flat.

The doublet at $c a .158 \mathrm{~cm}^{-1}$ remains unassigned in this scheme and may be related to the Raman band at ca. $160 \mathrm{~cm}^{-1}$ observed in an earlier study of glassy hydrogen halide aqueous solutions. This band was assigned to the stretching vibrations of the $\mathrm{OH}$... I hydrogen bond [8]. In the same way the asymmetric band at $c a .235 \mathrm{~cm}^{-1}$ has to be attributed to an optical mode [44] caused by specific positions and orientations of the hydrogen bonds within the local structures of S2; suggesting, perhaps, that our working model $4 \mathrm{w}_{\mathrm{I}}$ should adopt an S4 point group symmetry to better fit the experimental observations.

Coupled with the above, the calculated vibrational frequencies, listed in Tables 4 and 5, also help to rationalize the offset and broadening observed between the Raman spectra of S1 and S2 in the $\mathrm{OH}$ stretch region from 2800 to $3800 \mathrm{~cm}^{-1}$. According to these results, the spectral contour in this region is expected to be broadened and blue-shifted as the aquo-complexes squeeze in more water molecules. In particular the offset in band IV reflects an enhanced hydrogen bonding in the iodide hydration shells present in S2.

3.2. Ternary Systems: $H I-I_{2}-H_{2} \mathrm{O}, \mathrm{KI}-\mathrm{I}_{2}-\mathrm{H}_{2} \mathrm{O}$. The mole ratios $x_{\mathrm{I}_{2}} / x_{\mathrm{HI}}$ and $x_{\mathrm{H}_{2} \mathrm{O}} / x_{\mathrm{HI}}$ will be of particular significance in explaining the SRS and INS spectra, respectively, and therefore their values, for the ternary systems are given in Table 6, as an aid in the discussion of results of this section.

\subsection{1. $30-700 \mathrm{~cm}^{-1}$ Region}

We note that none of the ternary systems showed discernible Raman bands above $700 \mathrm{~cm}^{-1}$, mainly due to a strong fluorescence background at both $514.5 \mathrm{~nm}$ and $785 \mathrm{~nm}$. In the case of INS spectra, the overall picture is very similar, with the majority of spectral features appearing below $700 \mathrm{~cm}^{-1}$, with the exception of the water bending mode $c a$ $1600 \mathrm{~cm}^{-1}$. 
TABLE 7: Comparison of the INS and unscaled calculated frequencies, $\mathrm{cm}^{-1}$. Note: le—left edge; vw—very weak; sp—strong peak; bp—broad peak; re-right edge; h-hump; sh—shoulder; d—doublet; m—-medium; w—weak.

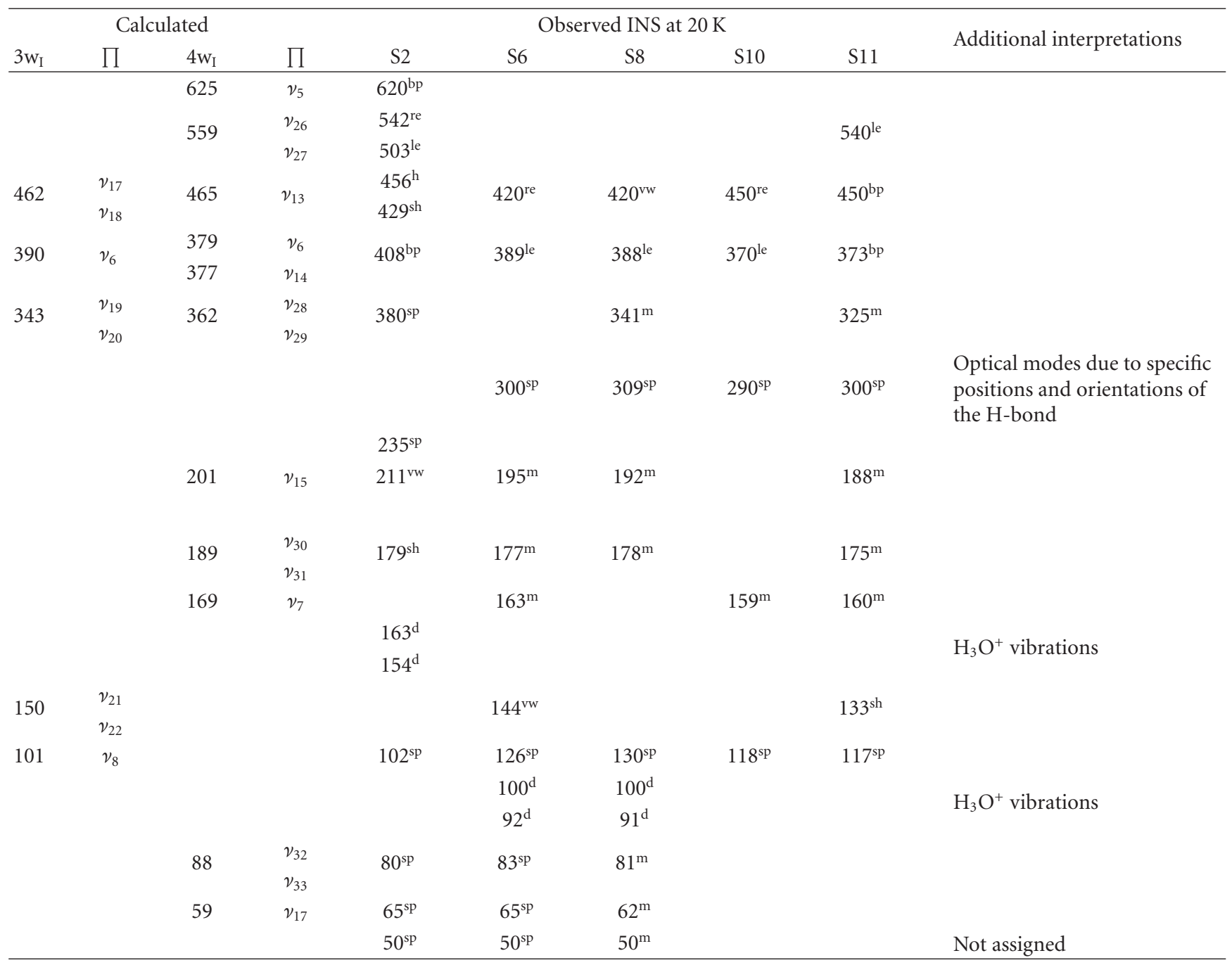

SRS Spectra. As for the binary system (see SRS Spectra Section 3.1.3) the $\mathrm{HI}-\mathrm{I}_{2}-\mathrm{H}_{2} \mathrm{O}$ system also exhibits a consistent set of 6 component bands [14]. These bands were located approximately $c a 85 \mathrm{~cm}^{-1}$ (very weak, broad and not always discernible), 112, 141, 166, 225 and $337 \mathrm{~cm}^{-1}$. Bands at $c a 85,112,141,225$, and $337 \mathrm{~cm}^{-1}$ correspond to the symmetric $\mathrm{I}_{3}{ }^{-}$ion, again present in this system. However, the most remarkable aspect of this system is the displacement of the band at $c a 166 \mathrm{~cm}^{-1}$, this varies from 161 to $170 \mathrm{~cm}^{-1}$, depending on the sample's composition. This is clearly shown in Figure 13(a), the band is related to the $\mathrm{I}^{-}\left(\mathrm{I}_{2}\right)_{n}$ species earlier discussed in Section 1.2 (a fuller discussion of this band and its displacement can be found elsewhere [14]).

In the $\mathrm{KI}-\mathrm{I}_{2}-\mathrm{H}_{2} \mathrm{O}$ system 6 bands were identified, a very weak band $c a 85 \mathrm{~cm}^{-1}$ and another five bands located $c a 110$, $140,166,224$, and $337 \mathrm{~cm}^{-1}$. The most notable aspect of this system is the change in relative intensities of bands at 110 and $166 \mathrm{~cm}^{-1}$ when compared to samples of similar composition but prepared with HI instead of KI. This might suggest that the nature of the metal cation and or the $\mathrm{pH}$ of the media have an effect in favouring, in the present case, the $\mathrm{I}_{3}{ }^{-}$species with equidistant I-I bonding.

Figure 13(b) shows the SRS spectra of both samples of the $\mathrm{KI}-\mathrm{I}_{2}-\mathrm{H}_{2} \mathrm{O}$ system. As was implied above, symmetric $\mathrm{I}_{3}{ }^{-}$ and $\mathrm{I}^{-}\left(\mathrm{I}_{2}\right)$ and $\mathrm{I}^{-}\left(\mathrm{I}_{2}\right)_{2}$ solvated species are present within the system; although it is apparent from the SRS spectrum of $\mathrm{S} 10$ that $\mathrm{I}^{-}\left(\mathrm{I}_{2}\right)$ is greatly suppressed, confirming the predominance of symmetric $\mathrm{I}_{3}{ }^{-}$as previously observed [45].

INS Spectra. It has been already mentioned that the mole ratio $x_{\mathrm{H}_{2} \mathrm{O}} / x_{\mathrm{HI}}$ is another influence on local structures present in the homogenous fluid phase of the HI- $\mathrm{I}_{2}-\mathrm{H}_{2} \mathrm{O}$ system, above all in the region of interest to the S-I cycle. Such influence was made evident by previous $a b$ initio calculations, which identified stable aquo-complexes of isolated, neutral $\mathrm{HI}$, and the ion pair $\mathrm{H}^{+} \mathrm{I}^{-}$. These complexes were found to be most stable for $x_{\mathrm{H}_{2} \mathrm{O}} / x_{\mathrm{HI}}$ mole ratios of 3 and 4 , respectively [15]. Lines of constant $x_{\mathrm{H}_{2} \mathrm{O}} / x_{\mathrm{HI}}$ mole ratio for integer values $3,4,5$ and 6 are shown in Figure 3. It is clear that the relative 

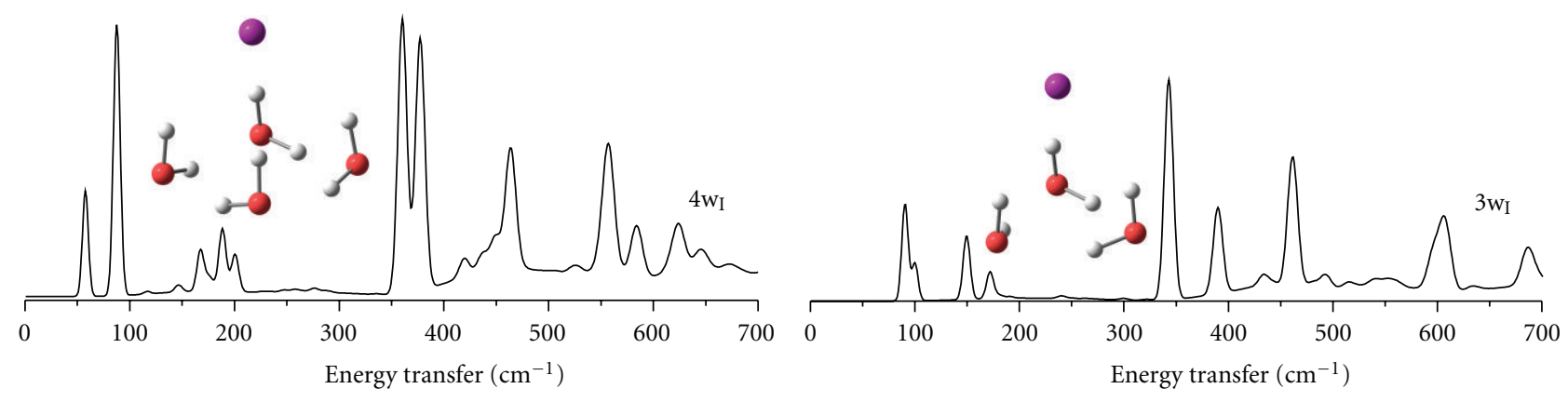

Figure 10: Calculated INS spectra of the two idealized models $4 \mathrm{w}_{\mathrm{I}}$ and $3 \mathrm{w}_{\mathrm{I}}$.

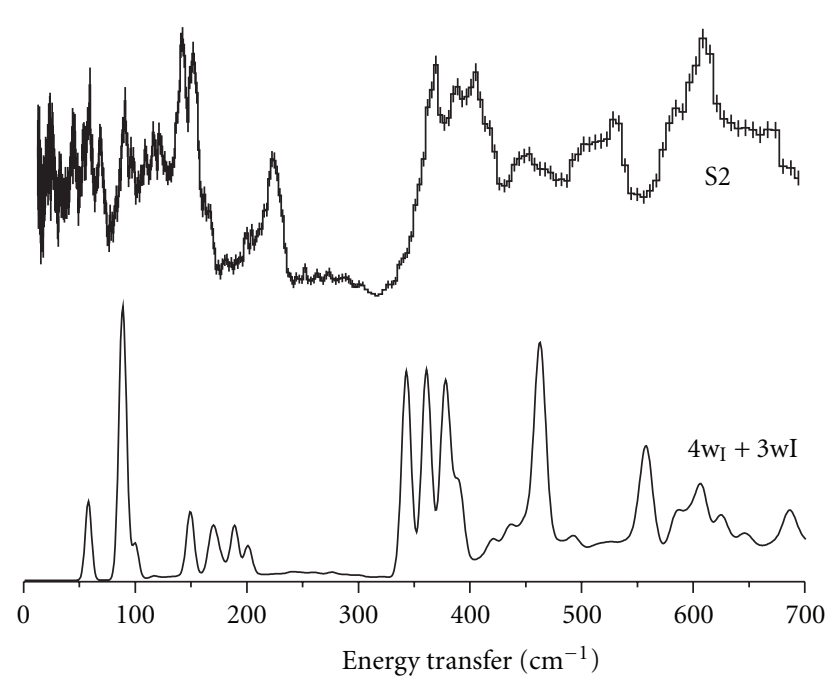

FIgURE 11: Theoretical INS spectrum, resulting from the sum of the calculated INS spectra of $4 \mathrm{w}_{\mathrm{I}}$ and $3 \mathrm{w}_{\mathrm{I}}$, compared against the experimental INS spectrum obtained from S2.

amount of water available to interact with $\mathrm{I}_{2}$-containing species of any kind is important in interpreting the solvation structures present in the homogeneous fluid region, and it is anticipated that a hexa-aquo complex will be important in diluted systems. We shall use molecular models of the HI$\mathrm{H}_{2} \mathrm{O}$ and $\mathrm{HI}-\mathrm{I}_{2}-\mathrm{H}_{2} \mathrm{O}$ systems to explore their dynamics.

Despite the explicit presence of iodine within the $\mathrm{HI}^{-} \mathrm{I}_{2}-$ $\mathrm{H}_{2} \mathrm{O}$ ternary system, spectra similar to those obtained from the $\mathrm{HI}-\mathrm{H}_{2} \mathrm{O}$ binary system were observed. The mole ratio $x_{\mathrm{H}_{2} \mathrm{O}} / x_{\mathrm{HI}}$ has clearly the same influence in producing local structures within the ternary system, as it did in the HI$\mathrm{H}_{2} \mathrm{O}$ binary system. Here, however, an extra parameter must be considered, the $x_{\mathrm{I}_{2}} / x_{\mathrm{HI}}$ mole ratio, which determines the capability of the iodide ion to coordinate an iodine molecule. Thus, if the $x_{\mathrm{I}_{2}} / x_{\mathrm{HI}}$ mole ratio is very close to the integers one (or two), there is a very good chance that the iodide ion couples to one (or two) iodine molecules, as discussed above.

These entities act as a core upon which water molecules grow into local structures, in the same way that the iodide ion acts for the binary system. However, for noninteger $x_{\mathrm{I}_{2}} / x_{\mathrm{HI}}$ mole ratios, there is competition between these two local structures.

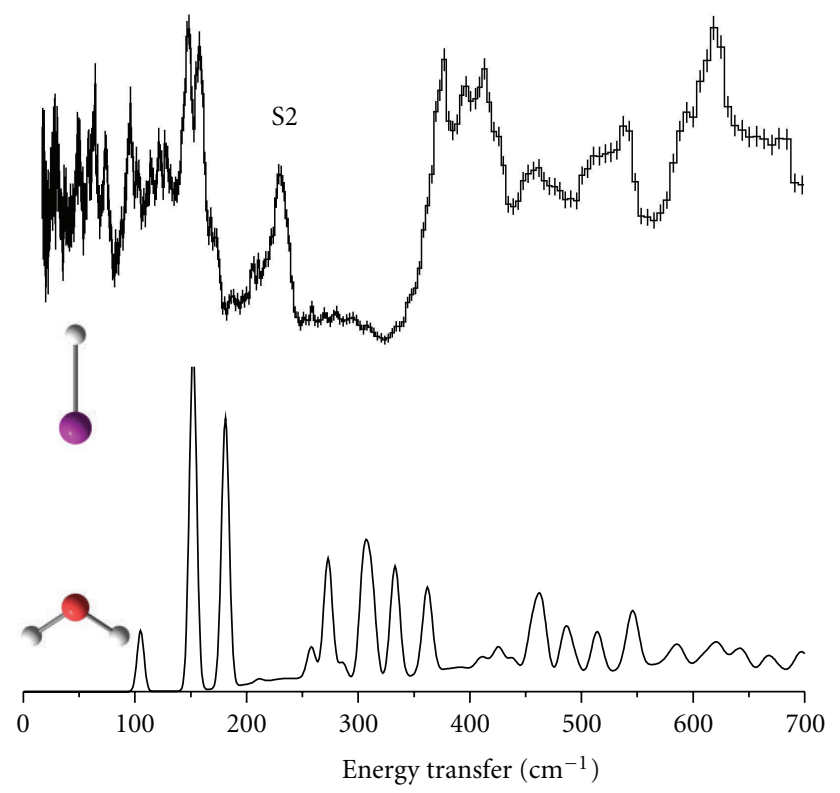

FIGURE 12: Comparison between the calculated INS spectra of the undissociated $\mathrm{HI}$-water cluster: $\mathrm{HI}\left(\mathrm{H}_{2} \mathrm{O}\right)$, aka $1 \mathrm{w}_{\mathrm{I}}$, and the experimental INS spectrum of S2.

Figure 14 compares two samples of the $\mathrm{HI}-\mathrm{I}_{2}-\mathrm{H}_{2} \mathrm{O}$ system, which presented evidence of local structure, against two samples of equivalent composition of the $\mathrm{KI}^{-} \mathrm{I}_{2}-\mathrm{H}_{2} \mathrm{O}$ system. These results are remarkable, and show that the samples corresponding to the $\mathrm{HI}-\mathrm{I}_{2}-\mathrm{H}_{2} \mathrm{O}$ system presented a similar picture to the one exhibited by the INS spectrum of S2. Furthermore, the lack of features in both INS spectra of the $\mathrm{KI}-\mathrm{I}_{2}-\mathrm{H}_{2} \mathrm{O}$ samples support the idea that the $\mathrm{K}^{+}$ion does not have a strong enough field to withdraw water molecules from the solvent structure [46]. In this case, the $\mathrm{I}_{2}$-containing anions $\left(\mathrm{I}^{-}, \mathrm{I}_{3}{ }^{-}, \mathrm{I}^{-}\left(\mathrm{I}_{2}\right), \mathrm{I}^{-}\left(\mathrm{I}_{2}\right)_{2}\right)$ are those responsible for disrupting the solvent structure.

It is unlikely that either the $4 \mathrm{w}_{\mathrm{I}}$ or $3 \mathrm{w}_{\mathrm{I}}$ models could account for the INS spectra of both ternary systems, given its intrinsically higher concentration of the $\mathrm{I}_{2}$-containing species. However, it is possible to interpret some of these experimental observations in terms of the INS spectrum of S2. 


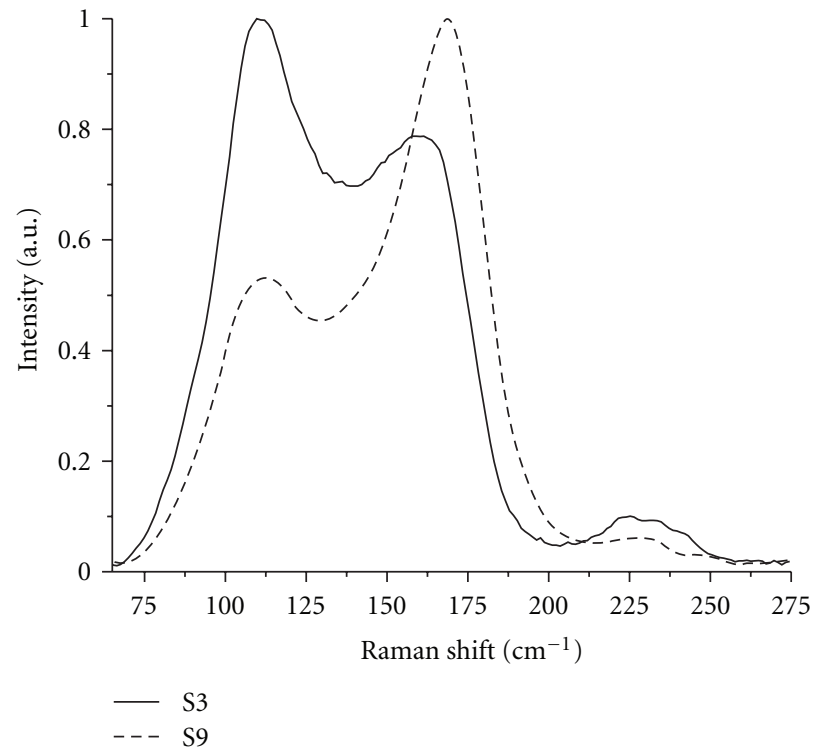

(a)

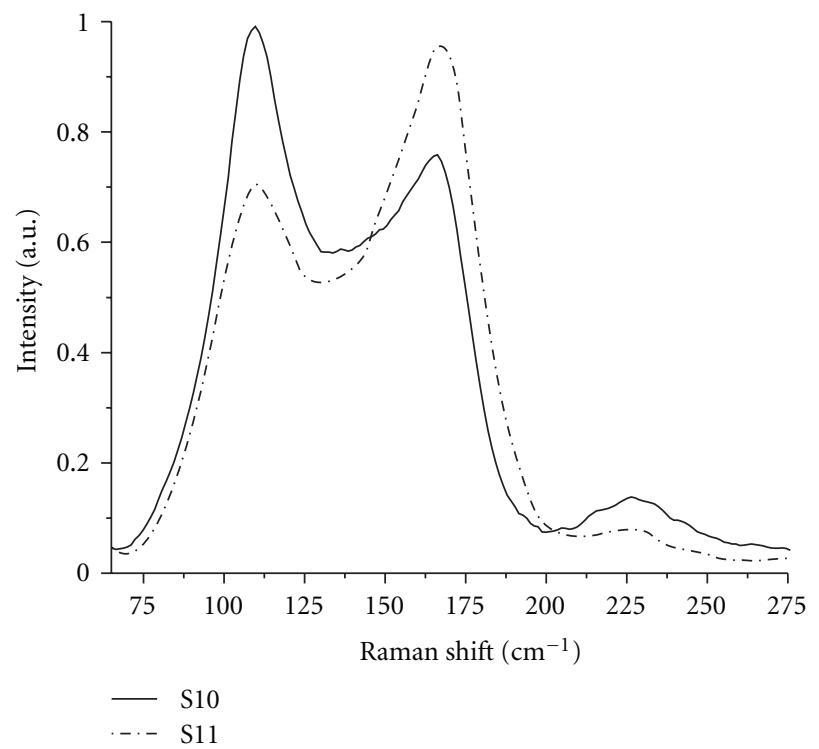

(b)

FIGURE 13: Raman spectra obtained at $298 \mathrm{~K}$ from samples of the (a) $\mathrm{HI}-\mathrm{I}_{2}-\mathrm{H}_{2} \mathrm{O}$ and (b) $\mathrm{KI}-\mathrm{I}_{2}-\mathrm{H}_{2} \mathrm{O}$ systems, within the region from $50 \mathrm{~cm}^{-1}$ to $275 \mathrm{~cm}^{-1}$, using $514.5 \mathrm{~nm}$ excitation source.

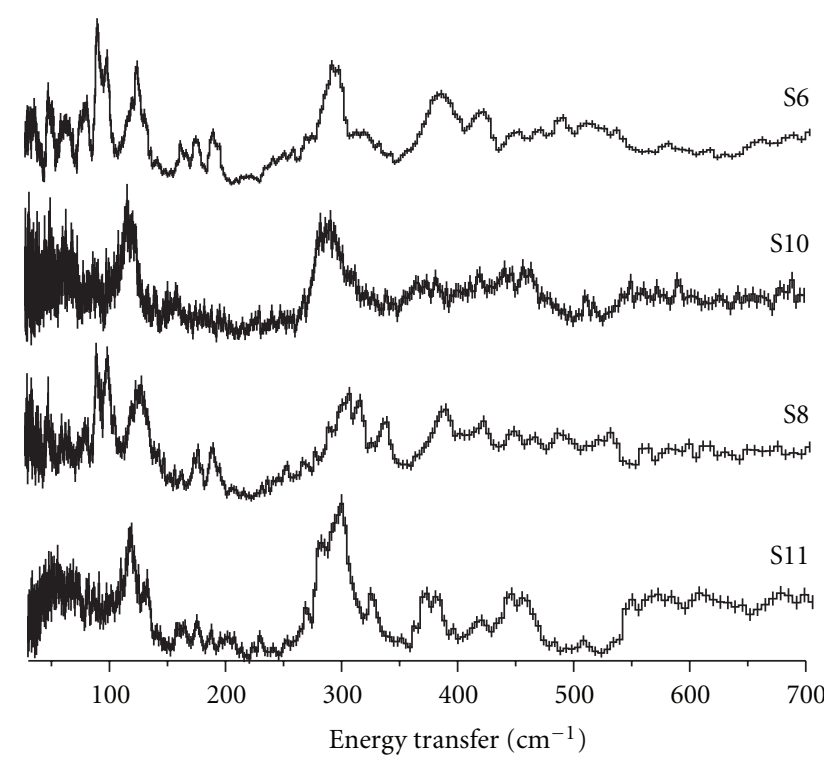

Figure 14: INS spectra, within the region from $30 \mathrm{~cm}^{-1}$ to $700 \mathrm{~cm}^{-1}$, of representative samples of the $\mathrm{HI}-\mathrm{I}_{2}-\mathrm{H}_{2} \mathrm{O}(\mathrm{S} 6, \mathrm{~S} 8)$ and $\mathrm{KI}-\mathrm{I}_{2}-\mathrm{H}_{2} \mathrm{O}(\mathrm{S} 10, \mathrm{~S} 11)$ ternary systems at $20 \mathrm{~K}$.

Also present in both spectra is a doublet at $c a .96 \mathrm{~cm}^{-1}$ with a strong resemblance to the $158 \mathrm{~cm}^{-1}$ doublet in S2, which was assigned, above, to deformations of the local structures, rather than stretching vibrations of the $\mathrm{OH} \cdots$ I as formerly invoked. Conversely, an alternative assignment for both doublets might link them with vibrations of the hydroxonium ion, explaining thus the remarkable frequency shift by force constant changes; this shift might also be expected in other hydroxonium bands. The occurrence of $\mathrm{H}^{+}$ as a counterion in samples where this doublet was observed reinforces such hypothesis.

Additional support to this new assignment scheme has been found through the abovementioned spectral simulation. Such results revealed that the stretching mode of the $\mathrm{OH}$. . I moiety within the complex ions: $4 \mathrm{w}_{\mathrm{I}}$ and $3 \mathrm{w}_{\mathrm{I}}$ occur at 91 and $101 \mathrm{~cm}^{-1}$, which could be attributed to bands at ca. 128 and $117 \mathrm{~cm}^{-1}$ for the $\mathrm{HI}-\mathrm{I}_{2}-\mathrm{H}_{2} \mathrm{O}$ and $\mathrm{KI}-\mathrm{I}_{2}-\mathrm{H}_{2} \mathrm{O}$ systems, respectively. This mode was also apparent in S2 and $\mathrm{S} 1$, although at a lower frequency, $c a .100 \mathrm{~cm}^{-1}$, in a much better agreement with the idealised models. As in the case of hydroxonium ions band, this mode is also susceptible frequency shift by force constant changes.

Other three bands at $c a .163,177$, and $192 \mathrm{~cm}^{-1}$ were identified in the INS spectrum of S6 $\left(x_{\mathrm{I}_{2}} / x_{\mathrm{HI}}=0.85\right)$, they seem to relate to a triad observed in $4 \mathrm{w}_{\mathrm{I}}$, which have been assigned to compression and distortions of the aquocomplex as a whole. Evidence of such vibrational modes is also found in the spectrum of sample S8. With respect to the $\mathrm{KI}-\mathrm{I}_{2}-\mathrm{H}_{2} \mathrm{O}$ system, such bands are very weak and hardly discerned in samples S10 and S11.

A very broad and prominent band located at $300 \mathrm{~cm}^{-1}$ for the HI- $\mathrm{I}_{2}-\mathrm{H}_{2} \mathrm{O}$ system (and $c a .290 \mathrm{~cm}^{-1}$ for the KI$\mathrm{I}_{2}-\mathrm{H}_{2} \mathrm{O}$ ) has been attributed to an optical mode caused by specific positions and orientations of the hydrogen bonds within the local structures of the ternary systems [44]. This is a different mode to that described for S2 above, and the presence of either should be taken as evidence of particular hydrogen bonded structures occurring within a given system.

A summary of all the working assignments given for INS spectra of the binary and ternary systems, in the range 30$700 \mathrm{~cm}^{-1}$, is shown in Table 7 . 
3.3. The Azeotrope Scenario. The azeotrope of the $\mathrm{HI}-\mathrm{H}_{2} \mathrm{O}$ [10] system and the pseudoazeotrope of $\mathrm{HI}-\mathrm{I}_{2}-\mathrm{H}_{2} \mathrm{O}$ [7] are both considered detrimental to the process efficiency of the sulfur-iodine thermochemical cycle.

The INS spectra of samples lying either above or below azeotropic or pseudo-azeotropic compositions were rationalized in terms of their respective $x_{\mathrm{H}_{2} \mathrm{O}} / x_{\mathrm{HI}}$ mole ratios. Spectral evidence of molecular arrangements similar to those of the model complexes was found to predominate in samples whose content of hydrogen iodide (HI) is higher than that of its corresponding azeotrope or pseudoazeotrope. Our working models, $4 \mathrm{w}_{\mathrm{I}}$ and $3 \mathrm{w}_{\mathrm{I}}$, although stables depend strongly on relative weak interactions, that is, hydrogen bonding, which somehow explain the particular behaviour of $\mathrm{HI}_{x}$ in one of the engineering approaches to the final stage of the SI-TC, the hydrogen production through direct decomposition of $\mathrm{HI}_{x}$. Thus when $\mathrm{HI}_{x}$ is deficient in water $\left(x_{\mathrm{H}_{2} \mathrm{O}} / x_{\mathrm{HI}}<4\right)$, as it occurs above the pseudoazeotrope composition where not enough water molecules are longer available to stabilize the ionically dissociated $\mathrm{HI}_{x}$, the iodide anion $\left(\mathrm{I}^{-}\right)$recombines with one of the protons $\left(\mathrm{H}^{+}\right)$, and volatile hydrogen iodide, gets evaporated from the surface, which is ultimately decomposed into iodine $\left(\mathrm{I}_{2}\right)$ and hydrogen $\left(\mathrm{H}_{2}\right)$. Such molecular regime agrees with the observation that in systems exhibiting higher HI mole fractions $\left(x_{\mathrm{HI}}\right)$ than in the pseudoazeotrope, the SI-TC yields higher hydrogen pressures at the output [7], and it is further supported by similar chemical behaviour reported for other hydrogen halides [47].

\section{Conclusions}

In the present paper, the capabilities of both SRS and INS have been exploited to generate a more detailed and complete model of the $\mathrm{HI}_{x}$ phase of the GA SI-TC. For this purpose, a set of representative samples of the aqueous $\mathrm{HI}-\mathrm{H}_{2} \mathrm{O}$ binary system, and both aqueous $\mathrm{HI}-\mathrm{I}_{2}-\mathrm{H}_{2} \mathrm{O}$ and $\mathrm{KI}-\mathrm{I}_{2}-$ $\mathrm{H}_{2} \mathrm{O}$ ternary systems were examined. Whereas SRS revealed features corresponding to hydroxonium ions and hydration shells and ultimately confirmed the coexistence of solvated $\mathrm{I}_{2}$-containing species such as $\mathrm{I}_{3}^{-}, \mathrm{I}^{-}\left(\mathrm{I}_{2}\right)$, and $\mathrm{I}^{-}\left(\mathrm{I}_{2}\right)_{2}$; INS, on the other hand, exposed the occurrence of local structures at $\mathrm{HI}$ concentrations higher than those observed in both HI$\mathrm{H}_{2} \mathrm{O}$ and $\mathrm{HI}-\mathrm{I}_{2}-\mathrm{H}_{2} \mathrm{O}$ azeotropes. These local structures were then interpreted in terms of a rather simplified and empirical approach, in which two idealized models $\left(4 \mathrm{w}_{\mathrm{I}}, 3 \mathrm{w}_{\mathrm{I}}\right)$ were used to explain the INS spectra. It is also noteworthy that these models not just satisfied the interpretation of the INS spectra, but also accounted for the azeotropic behaviour of the $\mathrm{HI}-\mathrm{H}_{2} \mathrm{O}$ and $\mathrm{HI}-\mathrm{I}_{2}-\mathrm{H}_{2} \mathrm{O}$ systems. This work will set the basis for a more profound chemical understanding of $\mathrm{HI}_{x}$, which is only possible with definite structural information currently lacking, but that can be acquired through the exploitation of small angle neutron diffraction with isotopic substitution.

\section{Acknowledgments}

The authors would like to thank Chris Sammons from the MERI at Sheffield Hallam University for giving access to their Raman facilities, also gratitude to Stewart Parker and "Timmy" Ramirez-Cuesta for the support provided during the operation of TOSCA at ISIS facilities. V. H. RamosSánchez wishes to thank his sponsor CONACYT (Mexican Government) for the award of a full scholarship. This research was funded by the European Community Sixth Framework Program Priority through the HYTHEC Project under contract number 502704.

\section{References}

[1] C. E. Bamberger, "Hydrogen production from water by thermochemical cycles; a 1977 update," Cryogenics, vol. 18, no. 3, pp. 170-183, 1978.

[2] C. E. Bamberger, J. Braunstein, and D. M. Richardson, "Thermochemical production of hydrogen from water," Journal of Chemical Education, vol. 55, no. 9, pp. 561-564, 1978.

[3] G. Marbán and T. Valdés-Solís, "Towards the hydrogen economy?" International Journal of Hydrogen Energy, vol. 32, no. 12, pp. 1625-1637, 2007.

[4] D. O'Keefe, C. Allen, G. Besenbruch et al., "Preliminary results from bench-scale testing of a sulfur-iodine thermochemical water-splitting cycle," International Journal of Hydrogen Energy, vol. 7, no. 5, pp. 381-392, 1982.

[5] J. H. Norman, G. E. Basenbruch, L. C. Brown, D. R. O'Keefe, and C. L. Allen, "Thermochemical water-splitting cycle, bench-scale investigations, and process engineering," Tech. Rep. GA-A16713, General Atomics Co., San Diego, Calif, USA, 1982.

[6] K. F. Knoche, H. Engels, and J. Thoennissen, "Direct dissociation of hydrogeniodide into hydrogen and iodine from $\mathrm{HI}, \mathrm{H}_{2} \mathrm{O}, \mathrm{I}_{2}$-solution," Advanced Hydrogen and Energy, vol. 4, pp. $449-455$.

[7] H. Engels and K. F. Knoche, "Vapor pressures of the system $\mathrm{HI} / \mathrm{HO} / \mathrm{I}$ and H," International Journal of Hydrogen Energy, vol. 11, no. 11, pp. 703-707, 1986.

[8] H. Kanno, "Raman study of aqueous HX solutions (X = F, Cl, $\mathrm{Br}$ and I) in both liquid and glassy states," Journal of Raman Spectroscopy, vol. 24, pp. 689-693, 1993.

[9] A. Giaconia, G. Caputo, A. Ceroli et al., "Experimental study of two phase separation in the Bunsen section of the sulfur-iodine thermochemical cycle," International Journal of Hydrogen Energy, vol. 32, no. 5, pp. 531-536, 2007.

[10] J. Haase, H. Naas, and H. Thumm, "Experimental investigation on the thermodynamic behavior of concentrated halogen hydrogen acids," Zeitschrift für Physikalische Chemie, vol. 37, pp. 210-229, 1963.

[11] R. H. Elder, G. H. Priestman, B. C. Ewan, and R. W. K. Allen, "The separation of $\mathrm{HI}$ in the sulphur-iodine thermochemical cycle for sustainable hydrogen production," Process Safety and Environmental Protection, vol. 83, no. 4 B, pp. 343-350, 2005.

[12] L. M. Levering, M. Roxana Sierra-Hernández, and H. C. Allen, "Observation of hydronium ions at the air-aqueous acid interface: vibrational spectroscopic studies of aqueous $\mathrm{HCl}$, $\mathrm{HBr}$, and HI," Journal of Physical Chemistry C, vol. 111, no. 25, pp. 8814-8826, 2007. 
[13] J. Milne, "A Raman spectroscopic study of the effect of ionpairing on the structure of the triiodide and tribromide ions," Spectrochimica Acta Part A, vol. 48, no. 4, pp. 533-542, 1992.

[14] V. H. Ramos-Sanchez, R. J. Jeans, and R. Devonshire, "Raman scattering studies of the condensed phase of the $\mathrm{HI}_{x}$ feed of the sulfur-iodine thermochemical cycle," International Journal of Energy Research, vol. 35, no. 3, pp. 189-208, 2011.

[15] S. Odde, B. J. Mhin, S. Lee, H. M. Lee, and K. S. Kim, "Dissociation chemistry of hydrogen halides in water," Journal of Chemical Physics, vol. 120, no. 20, pp. 9524-9535, 2004.

[16] R. L. Frost, K. L. Erickson, and M. L. Weier, "Hydrogen bonding in selected vanadates: a Raman and infrared spectroscopy study," Spectrochimica Acta-Part A, vol. 60, no. 10, pp. 24192423, 2004

[17] F. Rull, "Structural investigation of water and aqueous solutions by Raman spectroscopy," Pure and Applied Chemistry, vol. 74, no. 10, pp. 1859-1870, 2002.

[18] J. Li and A. I. Kolesnikov, "Neutron spectroscopic investigation of dynamics of water ice," Journal of Molecular Liquids, vol. 100, no. 1, pp. 1-39, 2002.

[19] P. C. H. Mitchell, S. F. Parker, A. J. Ramirez-Cuesta, and J. Tomkinson, in VibrationalSpectroscopy with Neutrons, p. 642, World Scientific Publishing, River Edge, NJ, USA, 1st edition, 2005.

[20] J. Tomkinson and T. C. Waddington, "Inelastic neutron scattering from zirconium borohydride," Journal of the Chemical Society, Faraday Transactions 2, vol. 72, pp. 1245-1250, 1976.

[21] N. S. Grace, "The Existence of Solid Polyiodides of Potassium at $25^{\circ}$ C," Journal of the Chemical Society, pp. 594-609, 1931.

[22] TOSCA, "A World Class Inelastic Neutron Spectrometer," http://www.isis.stfc.ac.uk/instruments/tosca/publications/ tosca-paper6538.pdf.

[23] D. Colognesi, M. Celli, F. Cilloco et al., "TOSCA neutron spectrometer: the final configuration," Applied Physics A: Materials Science and Processing, vol. 74, no. 1, pp. S64-S66, 2002.

[24] F. D. Vila and K. D. Jordan, "Theoretical study of the dipolebound excited states of $\mathrm{I}\left(\mathrm{H}_{2} \mathrm{O}\right)$," Journal of Physical Chemistry A, vol. 106, no. 7, pp. 1391-1397, 2002.

[25] M. E. Dunn, T. M. Evans, K. N. Kirschner, and G. C. Shields, "Prediction of accurate anharmonic experimental vibrational frequencies for water clusters, $\left(\mathrm{H}_{2} \mathrm{O}\right), \mathrm{n}=2-5$," Journal of Physical Chemistry A, vol. 110, no. 1, pp. 303-309, 2006.

[26] M. J. Frisch, G. W. Trucks, H. B. Schlegel et al., Gaussian 03, Revision C.02, Gaussian, Wallingford, Conn, USA, 2004.

[27] C. Moller and M. S. Plesset, "Note on an approximation treatment for many-electron systems," Physical Review, vol. 46, pp. 618-622, 1934.

[28] D. Andrae, U. Häußermann, M. Dolg, H. Stoll, and H. Preuß, "Energy-adjusted ab initio pseudopotentials for the second and third row transition elements," Theoretica Chimica Acta, vol. 77, no. 2, pp. 123-141, 1990.

[29] A. Schäfer, C. Huber, and R. Ahlrichs, "Fully optimized contracted Gaussian basis sets of triple zeta valence quality for atoms Li to Kr," The Journal of Chemical Physics, vol. 100, no. 8, pp. 5829-5835, 1994.

[30] A. Schäfer, H. Horn, and R. Ahlrichs, "Fully optimized contracted Gaussian basis sets for atoms Li to Kr," The Journal of Chemical Physics, vol. 97, no. 4, pp. 2571-2577, 1992.

[31] A. J. Ramirez-Cuesta, "aCLIMAX 4.0.1, the new version of the software for analyzing and interpreting INS spectra," Computer Physics Communications, vol. 157, no. 3, pp. 226238,2004

[32] A. Milet, C. Struniewicz, R. Moszynski, and P. E. S. Wormer, "Theoretical study of the protolytic dissociation of $\mathrm{HCl}$ in water clusters," Journal of Chemical Physics, vol. 115, no. 1, pp. 349-356, 2001.
[33] G. M. Chaban, R. B. Gerber, and K. C. Janda, "Transition from hydrogen bonding to ionization in $(\mathrm{HCl})_{n}\left(\mathrm{NH}_{3}\right)_{n}$ and $(\mathrm{HCl})_{n}\left(\mathrm{H}_{2} \mathrm{O}\right)_{n}$ clusters: consequences for anharmonic vibrational spectroscopy," Journal of Physical Chemistry A, vol. 105, no. 36, pp. 8323-8332, 2001.

[34] R. Chenevert, M. Chamberland, M. Simard, and F. Brisse, "Complexes of 18-crown-6 with oxonium ions derived from transition metal chlorides and hydrochloric acid: 18crown-6 $\cdot \mathrm{H}_{3} \mathrm{O}^{+} \cdot \mathrm{FeCl}_{4}^{-}, 18$-crown- $6 \cdot \mathrm{H}_{3} \mathrm{O}^{+} \cdot \mathrm{InCl}_{4}^{-}$, (18-crown$\left.6 \cdot \mathrm{H}_{3} \mathrm{O}^{+}\right)_{2} \cdot \mathrm{Pd}_{2} \mathrm{Cl}_{6}^{2-}$," Canadian Journal of Chemistry, vol. 67, pp. 32-36, 1989

[35] V. Buch, J. Sadlej, N. Aytemiz-Uras, and J. P. Devlin, "Solvation and ionization stages of $\mathrm{HCl}$ on ice nanocrystals," Journal of Physical Chemistry A, vol. 106, no. 41, pp. 9374-9389, 2002.

[36] M. Mucha, T. Frigato, L. M. Levering et al., "Unified molecular picture of the surfaces of aqueous acid, base, and salt solutions," Journal of Physical Chemistry B, vol. 109, no. 16, pp. 7617-7623, 2005.

[37] P. Andersson, C. Steinbach, and U. Buck, "Vibrational spectroscopy of large water clusters of known size," European Physical Journal D, vol. 24, no. 1-3, pp. 53-56, 2003.

[38] D. Liu, G. Ma, L. M. Levering, and H. C. Allen, "Vibrational spectroscopy of aqueous sodium halide solutions and airliquid interfaces: observation of increased interfacial depth," Journal of Physical Chemistry B, vol. 108, no. 7, pp. 2252-2260, 2004.

[39] G. E. Walrafen, M. S. Hokmabadi, and W. H. Yang, "Raman investigation of the temperature dependence of the bending $\mathrm{V}$ and combination $\mathrm{V}+\mathrm{V}$ bands from liquid water," Journal of Physical Chemistry, vol. 92, no. 9, pp. 2433-2438, 1988.

[40] M. Freda, A. Piluso, A. Santucci, and P. Sassi, "Transmittance Fourier transform infrared spectra of liquid water in the whole mid-infrared region: temperature dependence and structural analysis," Applied Spectroscopy, vol. 59, no. 9, pp. 1155-1159, 2005.

[41] P. A. Giguère, C. Martel, and S. Turrell, "Hydrogen halidewater complexes in aqueous acids," Chemical Physics Letters, vol. 56, no. 2, pp. 231-234, 1978.

[42] H. Kanno and J. Hiraishi, "Existence of HO ions in glassy aqueous HX solutions (X = Cl and Br)," Chemical Physics Letters, vol. 107, no. 4-5, pp. 438-441, 1984.

[43] W. Kiefer and H. J. Bernstein, "The UV-laser excited resonance raman spectrum of the I ion," Chemical Physics Letters, vol. 16, no. 1, pp. 5-9, 1972.

[44] J. Li, "Inelastic neutron scattering studies of hydrogen bonding in ices," Journal of Chemical Physics, vol. 105, no. 16, pp. 67336755, 1996.

[45] R. Thomas and F. H. Moore, "Neutron Diffraction Studies of Polyiodides. I. Potassium Triiodide Monohydrate," Acta Crystallographica Section B, vol. B36, pp. 2869-2873, 1980.

[46] P. S. Leung and G. J. Safford, "A neutron inelastic scattering investigation of the concentration and anion dependence of low frequency motions of HO molecules in ionic solutions," Journal of Physical Chemistry, vol. 74, no. 21, pp. 3696-3709, 1970.

[47] V. E. Bondybey and M. K. Beyer, "How many molecules make a solution?" International Reviews in Physical Chemistry, vol. 21, no. 2, pp. 277-306, 2002. 


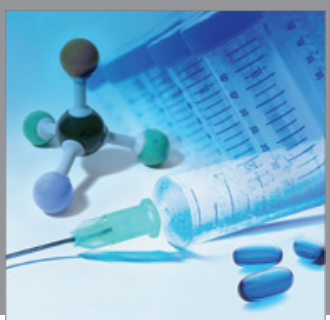

International Journal of

Medicinal Chemistry

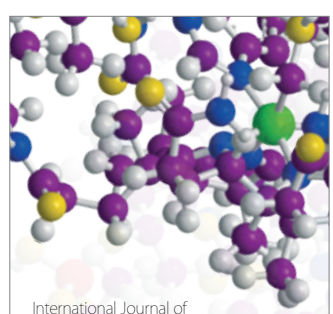

Carbohydrate Chemistry

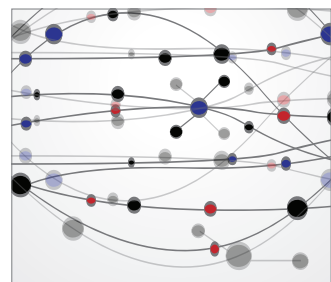

The Scientific World Journal
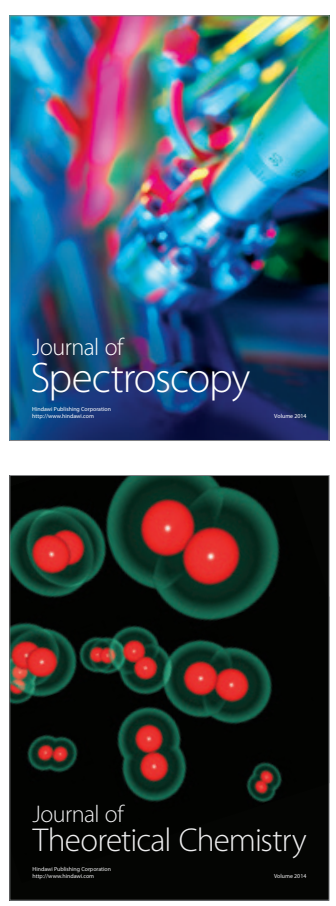
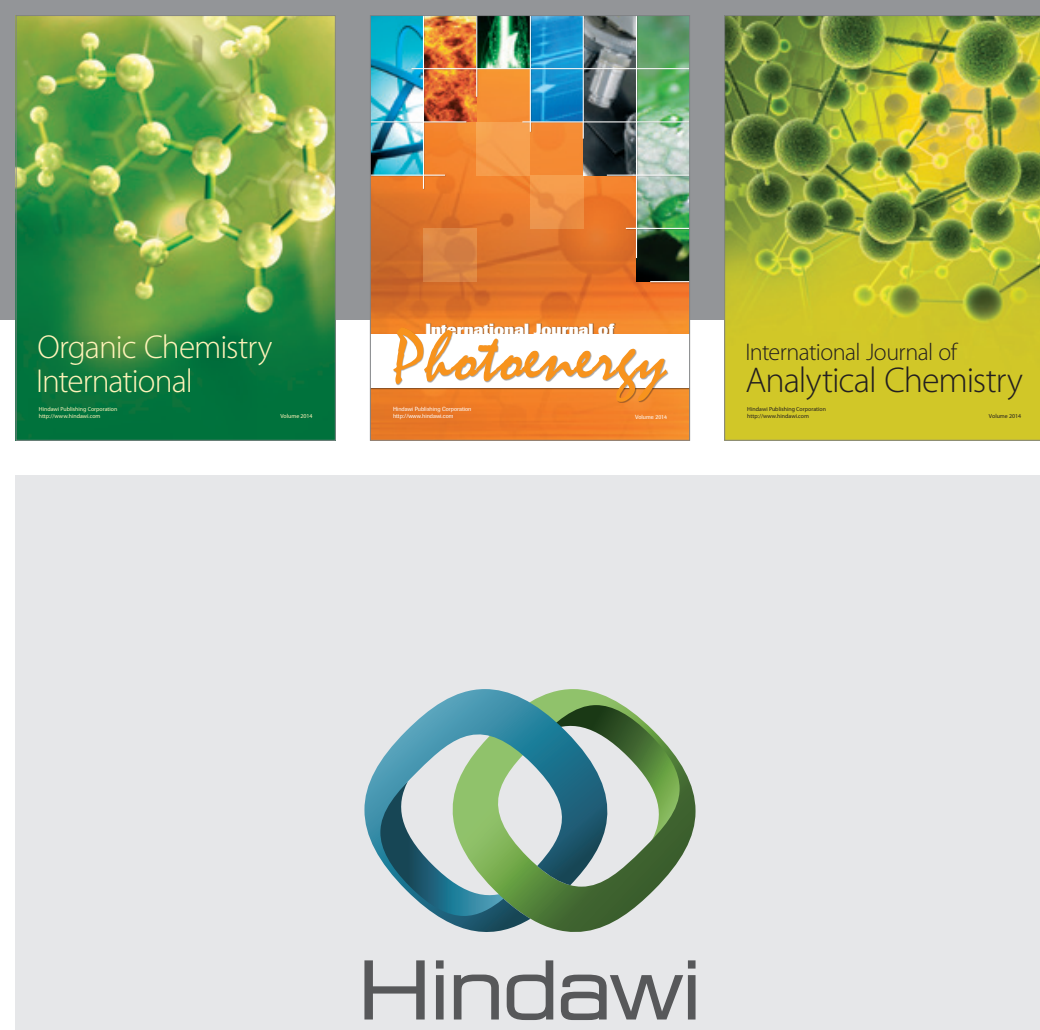

Submit your manuscripts at

http://www.hindawi.com
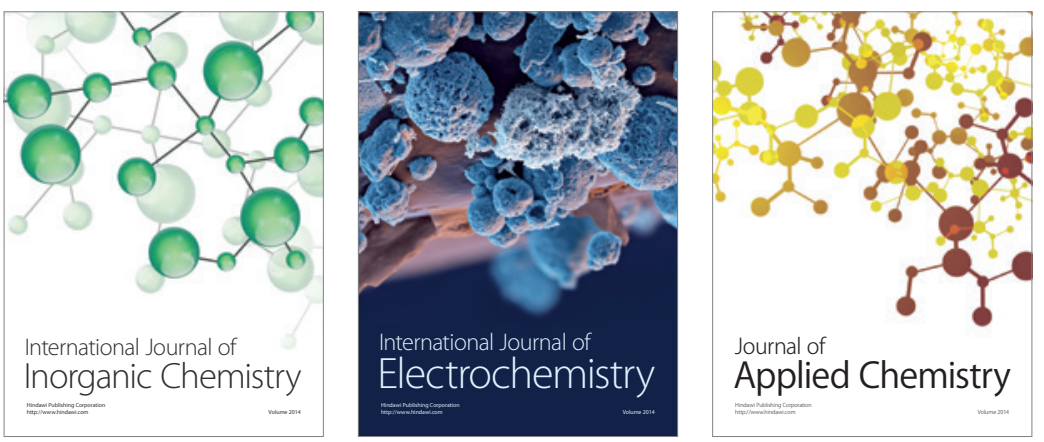

Journal of

Applied Chemistry
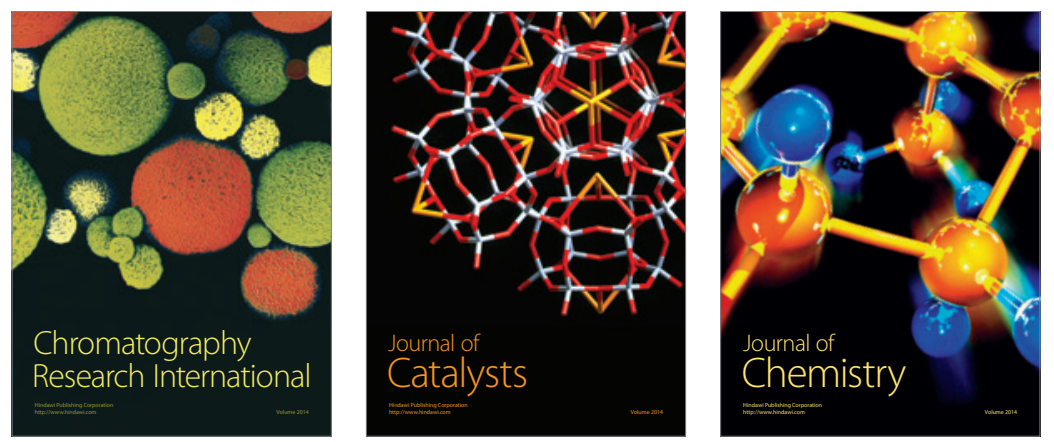
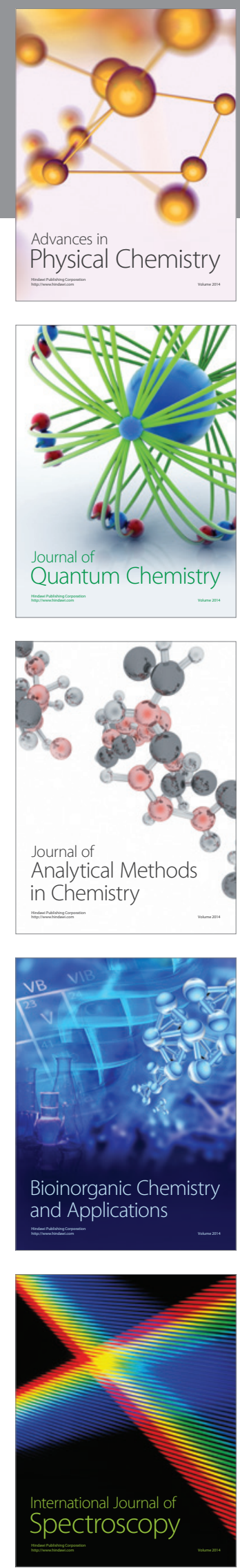